\title{
The NIST Quantitative Infrared Database
}

P. M. Chu, F. R. Guenther, G. C. Rhoderick, and W. J. Lafferty

National Institute of Standards and Technology,

Gaithersburg, MD 20899-0001

\author{
With the recent developments in Fourier \\ transform infrared (FTIR) spectrometers it \\ is becoming more feasible to place these \\ instruments in field environments. As a \\ result, there has been enormous increase in \\ the use of FTIR techniques for a variety of \\ qualitative and quantitative chemical mea- \\ surements. These methods offer the possi- \\ bility of fully automated real-time quantita- \\ tion of many analytes; therefore FTIR has \\ great potential as an analytical tool. \\ Recently, the U.S. Environmental Protection \\ Agency (U.S.EPA) has developed protocol \\ methods for emissions monitoring using \\ both extractive and open-path FTIR mea- \\ surements. Depending upon the analyte, the \\ experimental conditions and the analyte \\ matrix, approximately 100 of the hazardous \\ air pollutants (HAPs) listed in the 1990 \\ U.S.EPA Clean Air Act amendment \\ (CAAA) can be measured. The National \\ Institute of Standards and Technology \\ (NIST) has initiated a program to provide \\ quality-assured infrared absorption coeffi- \\ cient data based on NIST prepared primary \\ gas standards. Currently, absorption coeffi- \\ cient data has been acquired for approxi- \\ mately 20 of the HAPs. For each com-
}

\begin{abstract}
pound, the absorption coefficient spectrum was calculated using nine transmittance spectra at $0.12 \mathrm{~cm}^{-1}$ resolution and the Beer's law relationship. The uncertainties in the absorption coefficient data were estimated from the linear regressions of the transmittance data and considerations of other error sources such as the nonlinear detector response. For absorption coefficient values greater than $\left.1 \times 10^{-4} \mu \mathrm{mol} / \mathrm{mol}\right)^{-1} \mathrm{~m}^{-1}$ the average relative expanded uncertainty is $2.2 \%$. This quantitative infrared database is currently an ongoing project at NIST. Additional spectra will be added to the database as they are acquired. Our current plans include continued data acquisition of the compounds listed in the CAAA, as well as the compounds that contribute to global warming and ozone depletion.
\end{abstract}

Key words: air pollutants; database; gas standards; infrared spectrometer.

Accepted: December 3, 1998

Available online: http://www.nist.gov/jres

\section{Introduction}

With the recent developments in Fourier transform infrared (FTIR) spectrometers it is becoming more feasible to place these instruments in field environments [1]. As a result, there has been enormous increase in the use of FTIR techniques for a variety of qualitative and quantitative chemical measurements. These methods offer the possibility of fully automated real-time quantitation of many analytes; therefore FTIR has great potential as an analytical tool. Recently, the U.S. Environmental Protection Agency (U.S.EPA) has developed protocol methods for emissions monitoring using both extractive [2] and open-path [3] FTIR measurements. Depending upon the analyte, the experimental conditions and the analyte matrix, approximately 100 of the hazardous air pollutants (HAPs) listed in the 1990 U.S.EPA Clean Air Act amendment [4] (CAAA) can be measured.

Quantitative evaluation of field spectra requires a accurate reference spectral database. A user can generate quantitative reference spectra using a variety of approaches [5], however, this can be a time consuming and a costly process. Quantitative reference spectra are also available from several sources such as the U.S.EPA library [6] and the HITRAN spectral atlas and cross section library [7]. There are also several commercial 
sources including the quantitative libraries by Infrared Analysis [8], ${ }^{1}$ MIDAC Corporation [9], and Sprouse Scientific [10]. Comparisons of reference spectra from the available quantitative collections shows that the agreement of reported intensities is frequently $\pm 10 \%$ or worse. Impurity bands present in reference spectra can also interfere with the interpretation of field results.

The National Institute of Standards and Technology (NIST) has initiated a program to develop a qualityassured quantitative database of infrared spectra based on NIST prepared primary gas standards. Data acquisition is currently focused on the hazardous air pollutant species listed in the CAAA [4]. Since the database is designed to facilitate ground-based open-path FTIR measurements, the data were acquired with samples at room temperature and pressure broadened with nitrogen to one atmosphere. Currently, absorption coefficient data are available for approximately 20 HAPs on a U.S.EPA priority list. The data are stored in the standard JCAMP-DX format [11] to enable universal access to the data. Unapodized interferograms were acquired at $0.12 \mathrm{~cm}^{-1}$ resolution and have been processed to generate data at a number of different resolutions and apodizations, providing the users with data that closely match their experimental parameters. At each wavenumber in the spectrum the absorption coefficient $a$ is given as defined by the Beer-Lambert equation:

$$
I_{\mathrm{t}}(\nu)=I_{0}(\nu) 10^{-a(\nu) c l}
$$

where $I_{\mathrm{t}}(\nu)$ and $I_{0}(\nu)$ are the transmitted and incident light intensities, $c$ denotes the concentration of absorbing species, and $l$ is the path length. A digital signature accompanies each data file, allowing users to ensure the integrity and source of the data file and traceability to NIST.

This quantitative infrared database is an ongoing project at NIST. Additional spectra will be added to the database as they are acquired. Our current plans include continued data acquisition of the compounds listed in the CAAA (Appendix A) [4], as well as the compounds that contribute to global warming and ozone depletion.

\section{Materials and Methods}

\subsection{Materials}

The volatile organic compounds (VOCs) used to prepare these gas standards were obtained from

\footnotetext{
${ }^{1}$ Certain commercial equipment, instruments, or materials are identified in this paper to foster understanding. Such identification does not imply recommendation or endorsement by the National Institute of Standards and Technology, nor does it imply that the materials or equipment identified are necessarily the best available for the purpose.
}

commercial suppliers with the highest purity available, in most cases the stated purity was $99.9 \%$. Purity analyses were performed on the VOCs using gas chromatography with mass selective detection, differential scanning calorimetry, and Karl Fischer coulometric methods. Generally, the compounds were found to be $99.9 \%$ pure by gas chromatography and differential scanning calorimetry. The Karl Fischer titrations measured significant amounts of water in a number of the samples. Table 1 lists the samples in three categories; compounds that had a mass fraction of water greater than $0.1 \%$, compounds that had a mass fraction of water less than $0.1 \%$, and compounds that were not measured by the Karl Fischer method. These results were included in the gravimetric values.

Ultra-high-purity nitrogen $(99.9995 \%)$ was used as the balance gas. The primary gas standards were prepared in aluminum cylinders having an internal volume of $6 \mathrm{~L}$ and equipped with brass valves. The cylinders were pre-cleaned by a commercial supplier in a manner that minimizes contamination by trace hydrocarbons and halocarbons and then treated to deactivate the internal walls.

Table 1. Mass fraction of water in the pure compounds based on Karl Fischer coulometric measurements

\begin{tabular}{lll}
\hline $\begin{array}{c}\text { Compounds with } \\
<0.1 \% \\
\text { mass fraction } \\
\text { of water }\end{array}$ & $\begin{array}{c}\text { Compounds with } \\
>0.1 \% \\
\text { mass fraction } \\
\text { of water }\end{array}$ & \multicolumn{1}{c}{$\begin{array}{c}\text { Compounds } \\
\text { not measured }\end{array}$} \\
\hline Benzene & Acetone & Ethylene \\
Methanol & Ethanol & Bromomethane \\
2-Propanol & Ethyl acetate & Ethylene oxide \\
$n$-Butanol & Acetonitrile & 1,3-Butadiene \\
Vinyl acetate & Propylene oxide & Ethyl tert-butyl ether \\
Toluene & Methyl ethyl ketone & Methyl tert-butyl ether \\
Ethyl acrylate & Acrylonitrile & Sulfur dioxide
\end{tabular}

\subsection{Gravimetric Standards Preparation}

The procedure to prepare $\mu \mathrm{mol} / \mathrm{mol}$ (commonly referred to as part-per-million) level gravimetric gas standards of VOCs in nitrogen has been described in detail previously [12]. An evacuated, preweighed cylinder is fitted with the appropriate CGA-350 fitting equipped with a septum. A pure organic liquid is introduced into a gas tight syringe. The syringe containing the analyte is weighed on a microbalance with a capacity of $100 \mathrm{~g}$, and an uncertainty on the order of $5 \mu \mathrm{g}$. The fitting on the cylinder is heated with a heat gun to approximately $80^{\circ} \mathrm{C}$. Then the syringe needle is inserted into the septum while the cylinder valve is opened. If all the liquid is not immediately pulled into the evacuated cylinder, 
the syringe is heated gently. The syringe is then removed and weighed immediately and the weight of the organic material in the cylinder is determined by the difference in the syringe weights.

Next, ultra-high-purity nitrogen is added to the cylinder to a precalculated pressure, and the cylinder is weighed. The amount-of-substance fraction (commonly called mole fraction) of the VOCs is calculated from the weight of the pure VOCs and the weight of the nitrogen placed in the cylinder. The cylinders are weighed on a top-loading balance with a maximum capacity of $32 \mathrm{~kg}$, and an uncertainty on the order of $0.1 \mathrm{~g}$. All balances were calibrated with NIST-traceable weights. The final mole fractions of the gravimetric standards prepared for this work range from $1 \mu \mathrm{mol} / \mathrm{mol}$ to $1000 \mu \mathrm{mol} / \mathrm{mol}$, with the upper limit dependent on the vapor pressure of the individual compound. The standard concentrations were chosen based on the infrared band strengths. For standards up to $50 \mu \mathrm{mol} / \mathrm{mol}$, the expanded uncertainty (coverage factor of $k=2$ and thus a two standard deviation estimate, representing a $95 \%$ confidence interval) of the gravimetric values is $0.5 \%$ based on the uncertainties from the weighing procedures. For standards ranging from $50 \mu \mathrm{mol} / \mathrm{mol}$ to $1000 \mu \mathrm{mol} / \mathrm{mol}$, the expanded uncertainty in the gravimetric values is $0.2 \%$. Finally, the gas standards are analyzed using a gas chromatograph (GC) equipped with a flame-ionization detector. The data are fitted to a quadratic equation to verify the gravimetric procedure. The GC results confirm the gravimetric values to $<1.0 \%$.

\subsection{Data Acquisition}

FTIR spectra at $0.12 \mathrm{~cm}^{-1}$ resolution were acquired using a liquid-nitrogen cooled, mercury-cadmiumtelluride $(\mathrm{HgCdTe})$ detector with the optical bench under vacuum. The primary gas standards were flowed continuously at $1 \mathrm{~L} / \mathrm{min}$ at atmospheric pressure through a multipass absorption cell with a total volume of $7.5 \mathrm{~L}$ and a maximum path length of approximately $20 \mathrm{~m}$. The mirror spacing was measured with the cell disassembled. The total path length for one pass, including the additional length at the cell entrance and exit, measured $1.356 \mathrm{~m}$ with a standard uncertainty of approximately $0.001 \mathrm{~m}$. All other path lengths were derived from the mirror spacing [13]. The accuracy of this measurement was confirmed by comparing band intensities from laser studies [14] with the integrated band intensity of the $\nu_{1}+\nu_{3}$ band of $\mathrm{SO}_{2}$ obtained using this FTIR spectrometer [15]. The ambient temperature and pressure were monitored periodically throughout the measurements and referenced to a NIST-calibrated thermometer and capacitance manometer.

All background spectra were taken with ultra-high- purity nitrogen flowing through the cell. To test the stability of the sample concentration, several short scans were recorded first. Once it was verified that the ratio of consecutive scans showed no drift in the absorbance, a longer scan was recorded to obtain a signal-to-noise of 1000 or better. For the benzene-innitrogen mixtures, the transmittance was reproducible to $\pm 0.5 \%$ within 15 minutes.

Generally, the data were acquired from three different gravimetric concentrations at three different path lengths to generate a total of nine spectra. This procedure was chosen to provide a large dynamic range of data, so that both the strong and weak bands could be observed. Figure 1 shows the dynamic range of the transmission spectra acquired for the benzene samples. The final absorption coefficients were calculated from the nine transmission spectra and have been corrected to $296 \mathrm{~K}$ and $1.013 \times 10^{5} \mathrm{~Pa}$ (760.0 Torr) using the ideal gas law.

\subsection{Wavenumber Calibration Using Water Vapor}

The most convenient method for calibrating the wavenumber scale of the instrument is to use selected water vapor lines in both the (1200-1900) $\mathrm{cm}^{-1}$ and (3500-4000) $\mathrm{cm}^{-1}$ regions of the spectrum. These lines are always found in the spectrum and have been measured and tabulated by Toth [16], using the FT instrument at Kitt Peak, to a standard uncertainty of better than $0.0005 \mathrm{~cm}^{-1}$. Water vapor spectra were obtained with $1.3 \mathrm{kPa}$ (10 Torr) of ambient air in the multipass cell to minimize pressure-broadening effects. The water vapor peak positions were identified using the boxcar apodization function and second derivative peak search routine. The wavenumber shifts of selected water lines measured on our spectrometer compared to those of the Kitt Peak measurements are shown in Fig. 2. As expected, a small but significant shift is found which is linear with wavenumber. By fitting the ratio of the measured wavenumbers to the calibration wavenumbers, a correction factor was derived. When corrected wavenumbers are subtracted from those values given by Toth, the root-mean-square deviation obtained for 158 lines is $0.0042 \mathrm{~cm}^{-1}$ which is a good indication of the standard uncertainty of the frequency in our measurements. To maintain consistent wavenumber accuracy throughout this work, the wavenumber calibration is checked periodically and any time after the interferometer has been adjusted.

\subsection{Data Processing}

In all cases, unapodized interferograms were truncated to yield spectra at nominal resolutions of 


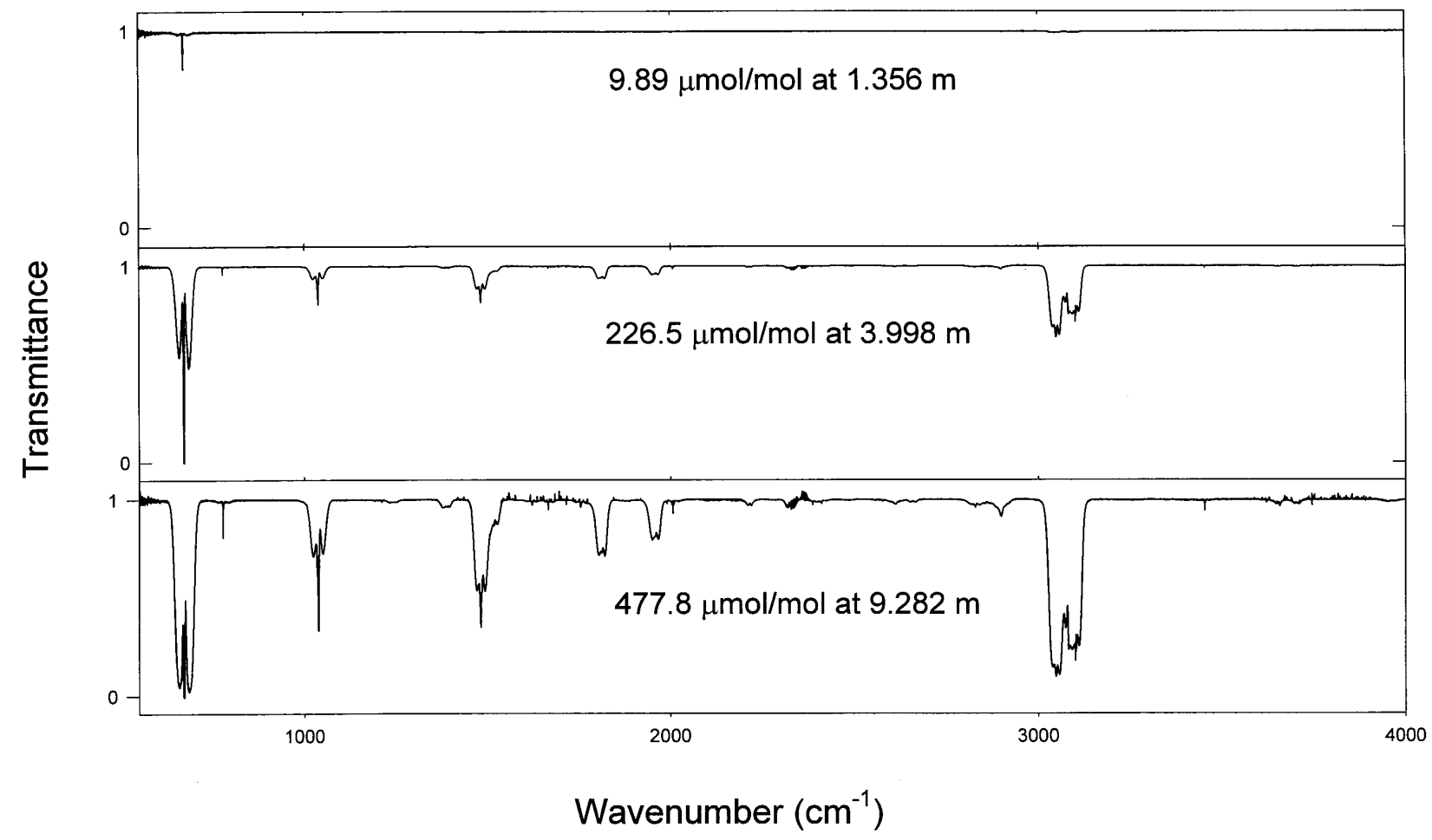

Fig. 1. Transmission spectra of benzene-in-nitrogen samples at three different concentrations and path length combinations.

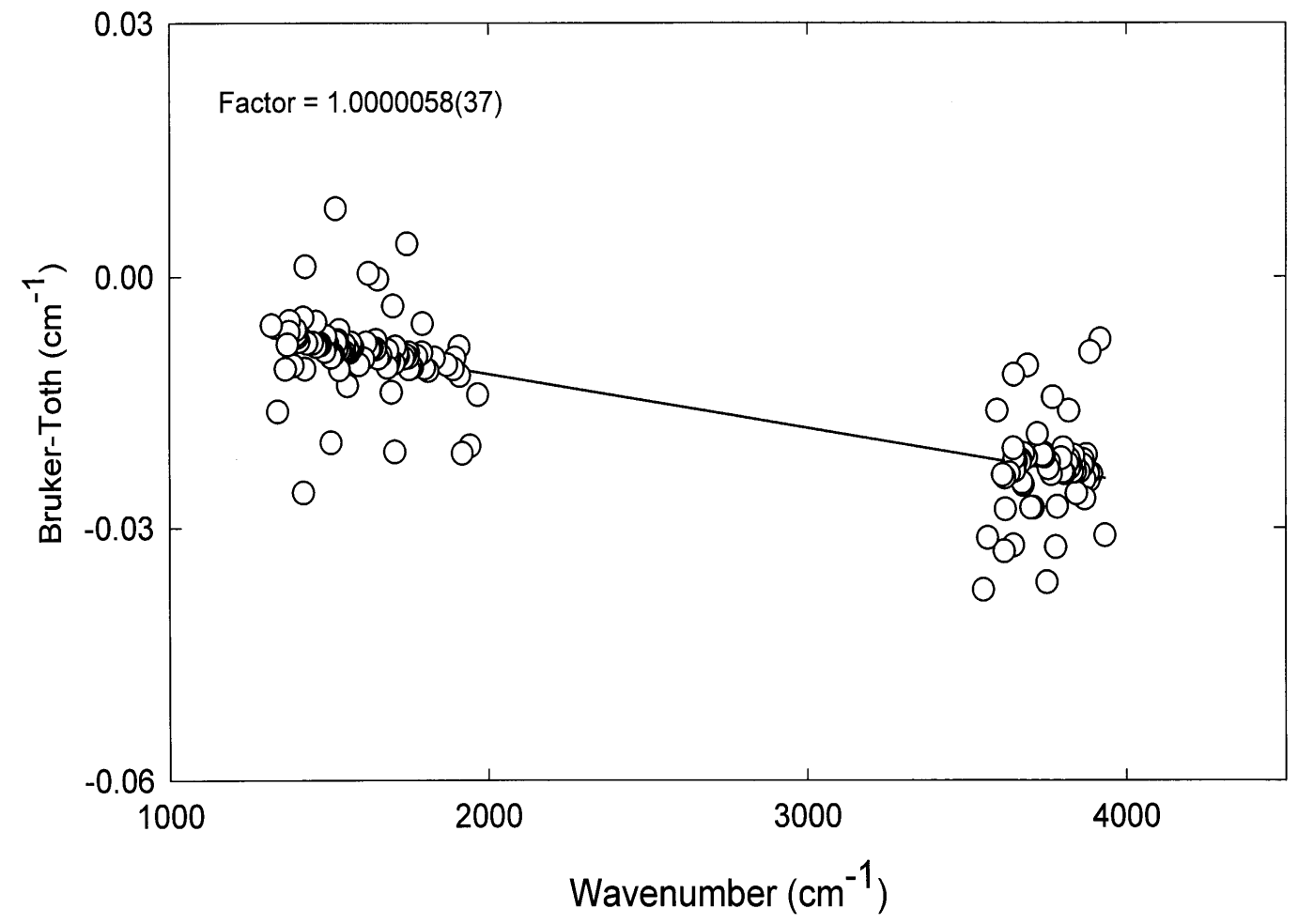

Fig. 2. Wavenumber calibration using selected water vapor lines. 
$0.125 \mathrm{~cm}^{-1}$. The resolution $\Delta \nu$ is given by the relationship $\Delta \nu \approx 1 / L$, where $L$ is the maximum retardation of the interferometer [17]. Then the interferograms were transformed using the Mertz phase correction, a zerofilling factor of two, a boxcar apodization function, and a detector nonlinear correction routine using the software package supplied with the instrument [18]. Pointby-point absorption coefficients were calculated from nine transmission spectra using the known concentrations and path lengths. Figure 3 shows a Beer's law plot for benzene at three representative wavelengths with the absorbance, $A=-\log _{10}(T)$ where $T$ is the transmittance. The uncertainty in the absorbance was derived from the uncertainty in the transmittance based on the relationship $\Delta A \sim(1 / T) \Delta T$. The data were modeled with a linear regression and a weighting factor given by $(1 / \Delta A)^{2}=(T / \Delta T)^{2}$. For transmittance values less than 0.02 , the transmittance was set to $1 \times 10^{-9}$. Generally, correlation coefficients $r^{2}=0.9997$ were obtained from the linear regressions, confirming the Beer's law behavior of this system.

Since many potential users collect data at different resolutions and apodization functions, an effort was made to provide the absorption coefficient data that would closely match the users' acquisition parameters. Deresolve [19], a program designed to degrade the resolution of high-resolution absorbance reference spectra, was used to generate the lower resolution data. Deresolve generates a transmittance spectrum from an absorbance spectrum then calculates the inverse Fourier-transform. The resulting interferogram is truncated and convoluted with a specified apodization function. Finally, the interferogram is transformed and converted back into an absorbance spectrum. It is anticipated that this program will accompany this database in future releases.

An absorbance spectrum for a given concentration and path length can be calculated from the tabulated absorption coefficient data by multiplying the absorption coefficient data by the desired mole fraction in units of $\mu \mathrm{mol} / \mathrm{mol}$ and by the desired path length in meters. It is important to emphasize that the absorbance spectrum, calculated as described above, will only be accurate at low absorbances where the absorbance is linear. The absorbance levels where non-linearities become an important factor depend on the resolution and apodization function of the spectrum as well as the natural width of the absorption feature.

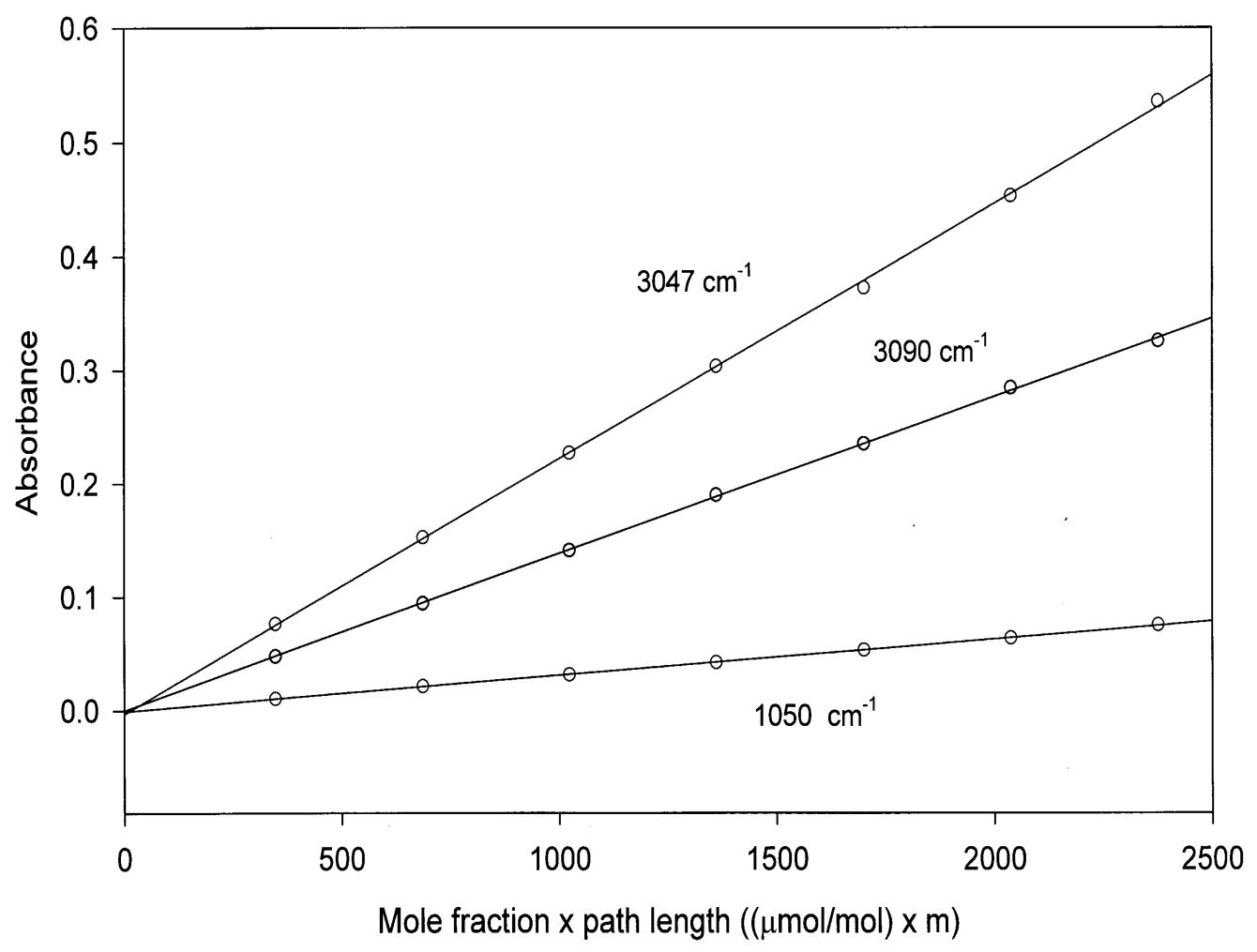

Fig. 3. Plot of the absorbance versus concentration multiplied by path length for selected lines along with the list squares fit to the data. The largest uncertainty in the absorbance is $\left(1.0 \times 10^{-3}\right)$ absorbance units. 


\section{Artifacts}

\subsection{Residual $\mathrm{H}_{2} \mathrm{O}, \mathrm{CO}$, and $\mathrm{CO}_{2}$}

Careful examination of the individual spectra indicated that residual water, carbon monoxide, and carbon dioxide features are present in the absorbance spectra. This indicates that there are different levels of $\mathrm{H}_{2} \mathrm{O}, \mathrm{CO}$, and $\mathrm{CO}_{2}$ in the background spectra compared to the sample spectra. Peak heights of $\mathrm{H}_{2} \mathrm{O}, \mathrm{CO}$, and $\mathrm{CO}_{2}$ lines were measured and compared to line intensities tabulated in the HITRAN database [7]. All of the $\mathrm{CO}$ and $\mathrm{CO}_{2}$ peak heights correspond to less than $\pm 2 \mu \mathrm{mol} / \mathrm{mol}$ of $\mathrm{CO}$ and $\mathrm{CO}_{2}$, where the negative value represents higher mole fractions of the contaminant in the background spectrum. Trace amounts of $\mathrm{CO}$ and $\mathrm{CO}_{2}$ in the ultra-high-purity nitrogen are likely to be the largest sources of the $\mathrm{CO}$ and $\mathrm{CO}_{2}$. The amount of water in the absorbance spectra generally varied from $-2 \mu \mathrm{mol} / \mathrm{mol}$ to $25 \mu \mathrm{mol} / \mathrm{mol}$. By comparing the water levels for all of the spectra, it was clear that the water levels depended on the compound as well as the concentration of the primary gas standards. This suggested that moisture in the pure VOCs is the largest source of water. This hypothesis was confirmed by Karl Fischer coulometric measurements that quantitated the moisture in the original VOCs. In fact, the mass fractions of water in the pure VOCs were in excellent agreement with the mass fraction of water in the gas standards calculated from the FTIR spectra.

\subsection{Electronic Noise}

During the course of this work, it was noted that consistent noise spikes occurred in the spectra at $1974.8 \mathrm{~cm}^{-1}, 2962.2 \mathrm{~cm}^{-1}$, and $3949.5 \mathrm{~cm}^{-1}$. These artifacts also appeared in spectra taken when no light reached the detector. An effort was made to eliminate these artifacts, but was not successful. Since these features are clearly artifacts, the noise spikes were eliminated from the spectra by replacing the data in a $0.4 \mathrm{~cm}^{-1}$ region centered about the spike with a line. The parameters for the line were obtained by using a linear function to model the data on either edge of these features.

\subsection{Baseline Drift}

An examination of all the transmission spectra indicates that there was a higher probability for the 3150 $\mathrm{cm}^{-1}$ to $3400 \mathrm{~cm}^{-1}$ region of the baseline to drift more than other regions. This artifact has been attributed to changes in the detector conditions during the course of the data acquisition. An effort was made to minimize these errors by taking background spectra at the beginning and end of a data run. The background spectrum that most closely matched the sample spectrum was used to calculate the transmission spectrum.

\section{Uncertainties}

The actual statistical or Type A [20] uncertainties in these measurements are represented by the uncertainties obtained from the linear regressions of the data. ORTHO [21], a Fortran subroutine that performs a least squares fit for a set of linear equations or power series was used to obtain the point-by-point absorption coefficients, $a$, along with the associated uncertainty in the absorption coefficients, $u_{\mathrm{A}}$. Figure $4 \mathrm{a}$ shows the absorption coefficient data calculated for ethylene and Fig. $4 \mathrm{~b}$ shows $u_{A}$ as a function of wavenumber. It is clear from Fig. $4 \mathrm{~b}$ that there are significantly larger uncertainties in the absorption coefficient data in the regions of the spectrum where $\mathrm{H}_{2} \mathrm{O}, \mathrm{CO}$, and $\mathrm{CO}_{2}$ absorb due to significant variations in the levels of these species in the background and sample spectra. Because it is difficult to completely remove these features from the spectra, the absorption coefficients are not certified in regions of the spectra where $\mathrm{H}_{2} \mathrm{O}\left[(1325-1900) \mathrm{cm}^{-1}\right.$ and (3550-3950) $\left.\mathrm{cm}^{-1}\right]$, CO $\left[(2050-2225) \mathrm{cm}^{-1}\right]$, and $\mathrm{CO}_{2}[(2295-2385)$ $\mathrm{cm}^{-1}$ ] absorb.

Figure 5 shows $u_{\mathrm{A}}$ as a function of the associated $a$, demonstrating that the uncertainty in the absorption coefficient can be approximated by a linear function of $a$, with $u_{\mathrm{A}} \approx m a+b$. Regions where $\mathrm{H}_{2} \mathrm{O}, \mathrm{CO}$, and $\mathrm{CO}_{2}$ absorb were not included in this analysis. Table 2 lists the slope $m$ and intercept $b$ parameters which can be used to approximate $u_{\mathrm{A}}$ for each compound contained in the database along with the mean and the standard deviation of the mean of the $m$ and $b$ parameters. These results indicate that the $b$ parameter for each compound can be replaced by the mean value for $b$.

The results in Table 2 also show that the relative Type A uncertainty, which can be approximated by $m$ for $a>1 \times 10^{-4}(\mu \mathrm{mol} / \mathrm{mol})^{-1} \mathrm{~m}^{-1}$, is significantly larger for three compounds: benzene, bromomethane, and ethyl tert-butyl ether. The uncertainties reported for the gravimetic standards in Sec 2.2 are based only on the uncertainties in the weighing procedures. Additional factors can affect the final gravimetric concentration [22] and may be responsible for the uncertainties observed for benzene, bromomethane, and ethyl tertbutyl ether. For example, a compound may react with the cylinder walls. Ten additional benzene samples were intercompared with FTIR spectrometry and the integrated band absorbances for two of the standards used for the database were significantly different compared to the other benzene samples. An effort is currently underway to improve the benzene results. 


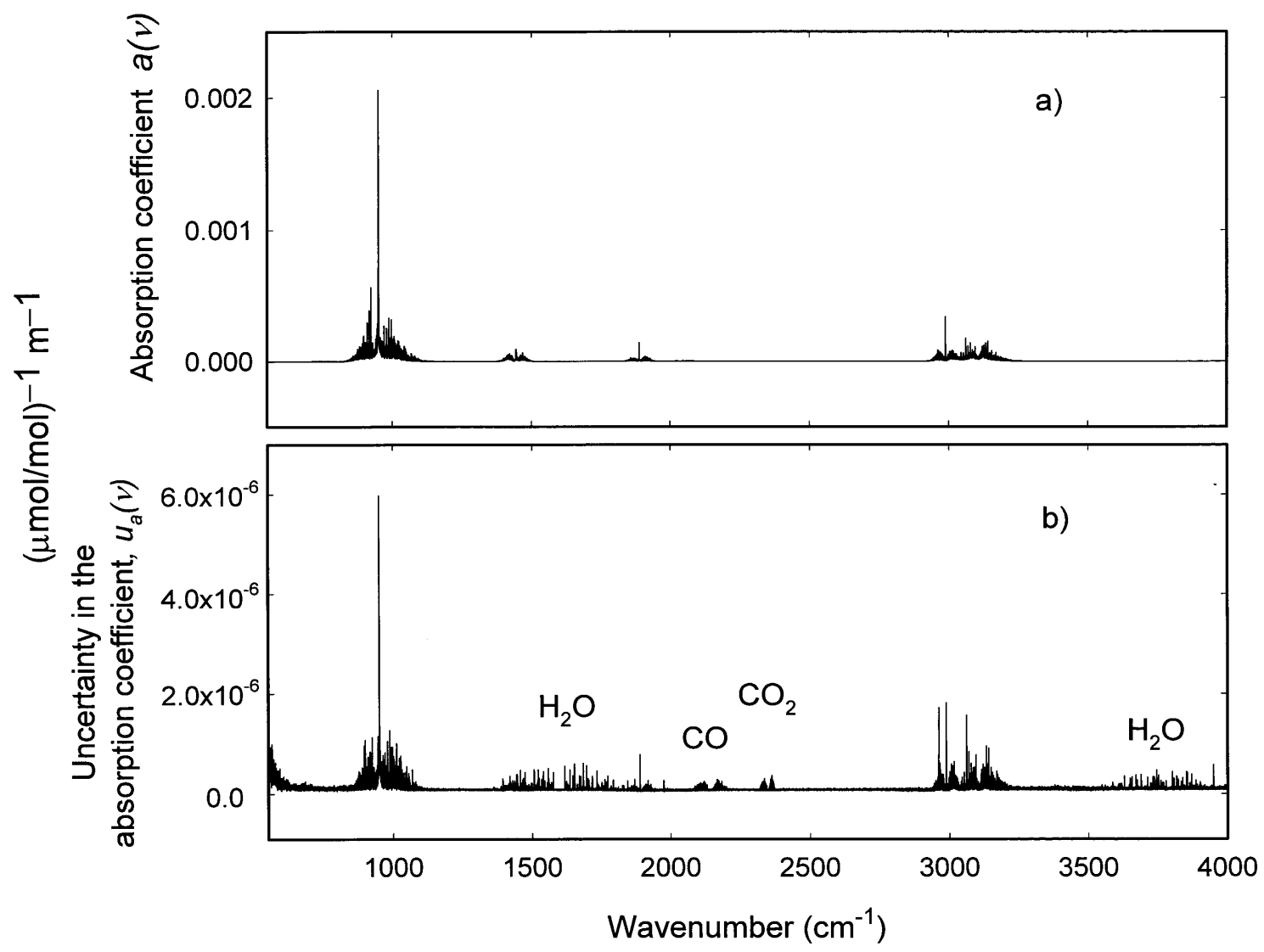

Fig. 4. a) Plot of the absorption coefficient, $a$ for ethylene. Data were prepared using $0.125 \mathrm{~cm}^{-1}$ resolution and boxcar apodization. b) Plot of the uncertainty in the absorption coefficient, $u_{a}$ for the absorption coefficient data in Fig. $4 \mathrm{a}$.

The nonlinear response of $\mathrm{HgCdTe}$ detectors has been documented [17]. This will add an additional nonstatistical Type B [20] relative uncertainty to the measurements, which has been included in the uncertainty analysis. An estimate of the standard uncertainty is $1.0 \%$ of the absorption coefficient and was obtained by comparing integrated band intensities for measurements made with a deuterated triglycine sulfate (DTGS) detector to measurements with a $\mathrm{HgCdTe}$ detector. The $\mathrm{HgCdTe}$ measurements were processed using the nonlinear correction routine supplied with the instrument [18].

Additional experimental variables contribute to the overall uncertainty of the absorption coefficients. Type $\mathrm{B}$ estimates of the relative standard uncertainties for the cell path length, pressure, temperature and FTIR stability are listed in Table 4. Estimates of the Type B relative uncertainty in the sample concentration where approximately a factor of ten lower than the sample to sample variability. Since gravimetric standards were measured for each compound, uncertainties in the absorption coefficients due to the sample concentrations are folded into the evaluation of the Type A uncertainties. An additional Type B uncertainty was included for samples, which showed the presence of water in the FTIR spectra, but were not tested for water content by the Karl Fischer method. The magnitude of this uncertainty component was estimated by the amount of water measured in the FTIR spectra.

The Type B relative uncertainties were combined by the equation:

$$
\begin{gathered}
u_{\mathrm{Brel}}= \\
\left(u_{l}^{2}+u_{\mathrm{press}}{ }^{2}+u_{\mathrm{temp}}{ }^{2}+u_{\mathrm{FTIR}}{ }^{2}+u_{\mathrm{NL}}^{2}+u_{\text {water }}{ }^{2}\right)^{1 / 2},
\end{gathered}
$$

where the relative standard uncertainties in the cell path length, pressure, temperature, FTIR stability, detector nonlinearities, and sample water content are denoted by $u_{l}, u_{\mathrm{press}}, u_{\mathrm{temp}}, u_{\mathrm{FTIR}}, u_{\mathrm{NL}}$, and $u_{\text {water }}$ respectively. The uncertainty attributed to the detector nonlinearities clearly dominate the Type B relative uncertainties. The combined Type B uncertainties are listed in Table 2. 


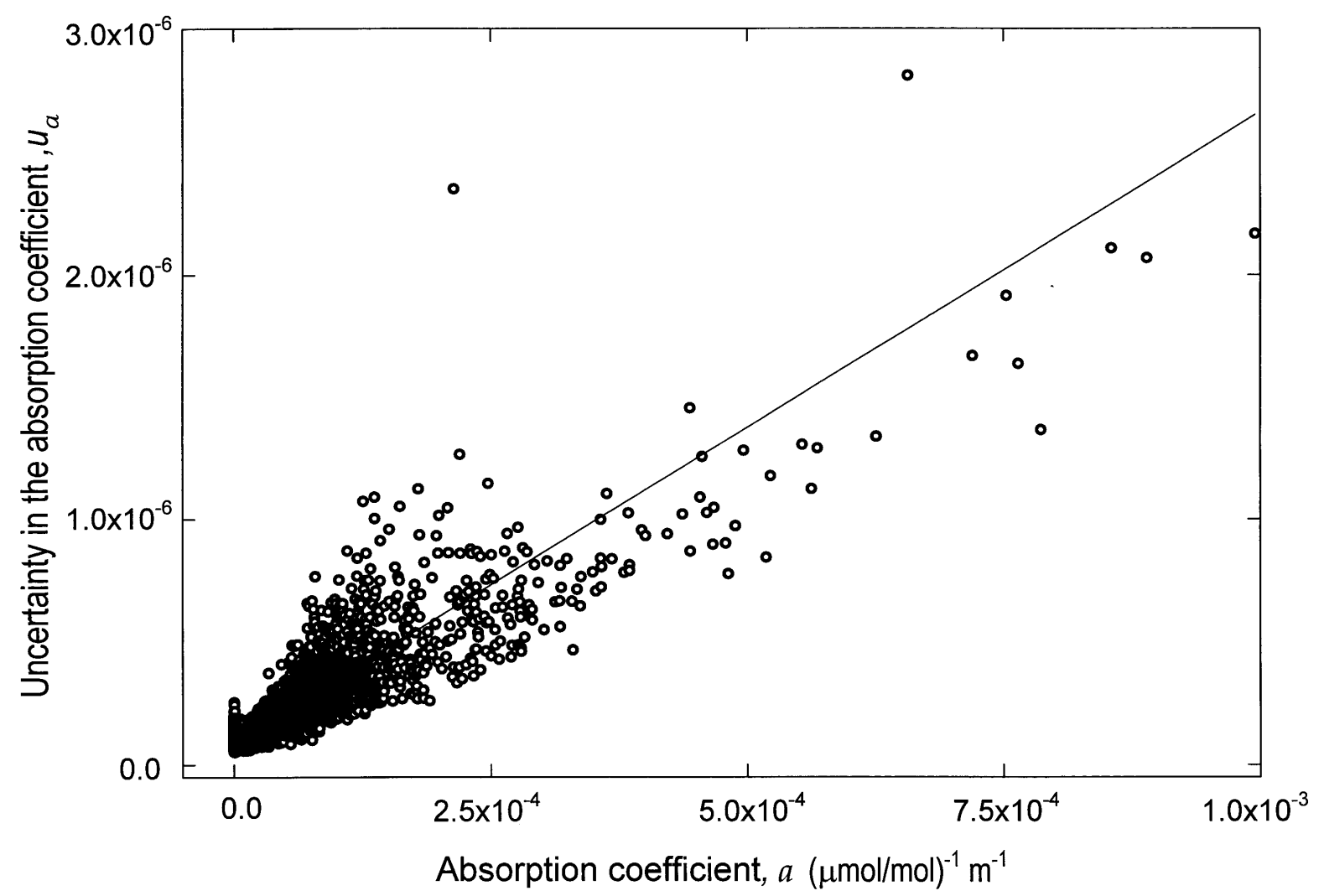

Fig. 5. The uncertainty in the absorption coefficient $u_{a}$ plotted as a function of the associated absorption coefficient a along with a linear approximation of $u_{\mathrm{a}} \approx m a+b$.

The expanded uncertainty is defined as $U=k u_{\mathrm{c}}$ with the standard uncertainty $u_{\mathrm{c}}$ determined from the experimental Type A and Type B standard uncertainties and the coverage factor $k=2$. The Type A and Type B uncertainties were combined as:

$$
\begin{gathered}
U=2\left(u_{\mathrm{A}}^{2}+\left(u_{\mathrm{Brel}} a\right)^{2}\right)^{1 / 2} \approx 2\left((m a+b)^{2}+\right. \\
\left.\left(u_{\mathrm{Brel}} a\right)^{2}\right)^{1 / 2} .
\end{gathered}
$$

$U$ can be simplified to:

$$
U \approx 2\left(B a^{2}+C a+D\right)^{1 / 2}
$$

where the coefficients $B, C$, and $D$ are listed in Table 3. The value of the absorption coefficient at a given wavelength is asserted to lie in the interval defined by $(a \pm U)$ with a level of confidence of approximately $95 \%$. In the relationship between $U$ and $a, D$ represents the uncertainty in the baseline. As the absorption coefficient gets larger, the $\mathrm{Ba}^{2}$ term dominates. For values of $a$ greater than $1 \times 10^{-4}(\mu \mathrm{mol} / \mathrm{mol})^{-1} \mathrm{~m}^{-1}$, the relative expanded uncertainty can be expressed as $U_{\text {rel }} \approx 2 B^{1 / 2}$ as listed in Table 3.

\section{Summary}

In response to the growing interest in quantitative gas measurements using FTIR spectrometry, NIST has initiated a program to develop a quality-assured quantitative database of infrared spectra based on NIST prepared primary gas standards. The database currently has absorption coefficient data for twenty-one compounds that are listed in the 1990 USEPA Clean Air Act Amendment. For each compound, the absorption coefficient spectrum was calculated using nine transmittance spectra at $0.12 \mathrm{~cm}^{-1}$ resolution and the Beer's law relationship. The uncertainties in the absorption coefficient data were estimated from the linear regressions of the absorbance data and considerations of other error sources such as the nonlinear detector response. 
Table 2. Type A and Type B standard uncertainties for each compound

\begin{tabular}{lccc}
\hline \hline $\begin{array}{l}\text { Compound } \\
\text { name }\end{array}$ & $\begin{array}{c}\text { Type A } \\
\sigma_{a} \approx m a+b\end{array}$ & $\begin{array}{c}\text { Type B } \\
u_{\text {Brel }} \\
\text { relative } \\
\text { uncertainty }\end{array}$ \\
& $\begin{array}{c}\text { Slope } \\
m\end{array}$ & $\begin{array}{c}\text { Intercept } \\
b\end{array}$ & 0.010 \\
Benzene & $1.3 \times 10^{-2}$ & $9.9 \times 10^{-8}$ & 0.010 \\
Ethylene & $2.6 \times 10^{-3}$ & $8.8 \times 10^{-8}$ & 0.010 \\
Acetone & $5.2 \times 10^{-3}$ & $4.9 \times 10^{-8}$ & 0.010 \\
Ethanol & $8.8 \times 10^{-4}$ & $2.8 \times 10^{-7}$ & 0.010 \\
Methanol & $2.0 \times 10^{-3}$ & $2.7 \times 10^{-7}$ & 0.010 \\
2-Propanol & $2.0 \times 10^{-3}$ & $7.6 \times 10^{-8}$ & 0.010 \\
Ethyl acetate & $1.9 \times 10^{-3}$ & $2.7 \times 10^{-7}$ & 0.010 \\
$n$-Butanol & $7.9 \times 10^{-4}$ & $5.7 \times 10^{-7}$ & 0.010 \\
Bromomethane & $1.0 \times 10^{-2}$ & $1.2 \times 10^{-7}$ & 0.010 \\
Acetonitrile & $9.5 \times 10^{-4}$ & $7.3 \times 10^{-8}$ & 0.010 \\
Ethylene oxide & $3.5 \times 10^{-3}$ & $1.6 \times 10^{-7}$ & 0.010 \\
Propylene oxide & $3.0 \times 10^{-3}$ & $1.7 \times 10^{-7}$ & 0.010 \\
Methyl ethyl ketone & $2.6 \times 10^{-3}$ & $2.6 \times 10^{-7}$ & 0.010 \\
Ethyl tert-butyl ether & $9.2 \times 10^{-3}$ & $-9.7 \times 10^{-9}$ & 0.012 \\
1,3-Butadiene & $3.4 \times 10^{-3}$ & $6.2 \times 10^{-8}$ & 0.010 \\
Acrylonitrile & $1.9 \times 10^{-3}$ & $9.3 \times 10^{-8}$ & 0.010 \\
Vinyl acetate & $2.3 \times 10^{-3}$ & $1.1 \times 10^{-7}$ & 0.010 \\
Toluene & $6.7 \times 10^{-3}$ & $2.1 \times 10^{-7}$ & 0.010 \\
Ethyl acrylate & $9.0 \times 10^{-4}$ & $1.8 \times 10^{-7}$ & 0.010 \\
Methyl tert -butyl ether & $2.4 \times 10^{-3}$ & $8.4 \times 10^{-8}$ & 0.010 \\
Sulfur dioxide & $2.3 \times 10^{-3}$ & $2.5 \times 10^{-7}$ & \\
& & & \\
Mean & $3.7 \times 10^{-3}$ & $6.3 \times 10^{-7}$ & \\
Standard deviation of the mean & $1.7 \times 10^{-4}$ & & \\
& & & \\
\hline & & &
\end{tabular}

Table 3. Final uncertainty coefficients for each compound where the expanded uncertainty is expressed by, $U \approx 2\left(B a^{2}+C a+D\right)^{1 / 2}$. For values of $a>1 \times 10^{-4}$, the relative expanded uncertainty can be simplified to $U_{\text {rel }} \approx 2 B^{1 / 2}$

\begin{tabular}{|c|c|c|c|c|}
\hline Compound & $B$ & $C$ & $D$ & $\begin{array}{c}\text { Relative } \\
\text { expanded } \\
\text { uncertainty } \\
\text { for } \\
a>1 \times 10^{-4}\end{array}$ \\
\hline Benzene & $2.6 \times 10^{-4}$ & $4.2 \times 10^{-9}$ & $2.7 \times 10^{-14}$ & $3.3 \%$ \\
\hline Ethylene & $1.1 \times 10^{-4}$ & $8.5 \times 10^{-10}$ & $2.7 \times 10^{-14}$ & $2.1 \%$ \\
\hline Acetone & $1.3 \times 10^{-4}$ & $1.7 \times 10^{-9}$ & $2.7 \times 10^{-14}$ & $2.3 \%$ \\
\hline Ethanol & $1.0 \times 10^{-4}$ & $2.9 \times 10^{-9}$ & $2.7 \times 10^{-14}$ & $2.0 \%$ \\
\hline Methanol & $1.0 \times 10^{-4}$ & $6.6 \times 10^{-10}$ & $2.7 \times 10^{-14}$ & $2.0 \%$ \\
\hline 2-Propanol & $1.0 \times 10^{-4}$ & $6.5 \times 10^{-10}$ & $2.7 \times 10^{-14}$ & $2.0 \%$ \\
\hline Ethyl acetate & $1.0 \times 10^{-4}$ & $6.3 \times 10^{-10}$ & $2.7 \times 10^{-14}$ & $2.0 \%$ \\
\hline n-Butanol & $1.0 \times 10^{-4}$ & $2.6 \times 10^{-10}$ & $2.7 \times 10^{-14}$ & $2.0 \%$ \\
\hline Bromomethane & $2.0 \times 10^{-4}$ & $3.3 \times 10^{-9}$ & $2.7 \times 10^{-14}$ & $2.8 \%$ \\
\hline Acetonitrile & $1.0 \times 10^{-4}$ & $3.1 \times 10^{-10}$ & $2.7 \times 10^{-14}$ & $2.0 \%$ \\
\hline Ethylene oxide & $1.1 \times 10^{-4}$ & $1.2 \times 10^{-9}$ & $2.7 \times 10^{-14}$ & $2.1 \%$ \\
\hline Propylene oxide & $1.1 \times 10^{-4}$ & $9.8 \times 10^{-10}$ & $2.7 \times 10^{-14}$ & $2.1 \%$ \\
\hline Methyl ethyl ketone & $1.1 \times 10^{-4}$ & $8.6 \times 10^{-10}$ & $2.7 \times 10^{-14}$ & $2.1 \%$ \\
\hline Ethyl tert-butyl ether & $1.9 \times 10^{-4}$ & $3.0 \times 10^{-9}$ & $2.7 \times 10^{-14}$ & $2.8 \%$ \\
\hline 1,3-Butadiene & $1.6 \times 10^{-4}$ & $1.1 \times 10^{-9}$ & $2.7 \times 10^{-14}$ & $2.5 \%$ \\
\hline Acrylonitrile & $1.0 \times 10^{-4}$ & $6.4 \times 10^{-10}$ & $2.7 \times 10^{-14}$ & $2.0 \%$ \\
\hline Vinyl acetate & $1.1 \times 10^{-4}$ & $7.7 \times 10^{-10}$ & $2.7 \times 10^{-14}$ & $2.1 \%$ \\
\hline Toluene & $1.4 \times 10^{-4}$ & $2.2 \times 10^{-9}$ & $2.7 \times 10^{-14}$ & $2.4 \%$ \\
\hline Ethyl acrylate & $1.0 \times 10^{-4}$ & $3.0 \times 10^{-10}$ & $2.7 \times 10^{-14}$ & $2.0 \%$ \\
\hline Methyl tert-butyl ether & $1.1 \times 10^{-4}$ & $7.8 \times 10^{-10}$ & $2.7 \times 10^{-14}$ & $2.1 \%$ \\
\hline Sulfur dioxide & $1.1 \times 10^{-4}$ & $2.7 \times 10^{-4}$ & & $2.1 \%$ \\
\hline
\end{tabular}


Table 4. Type B components of relative standard uncertainty

\begin{tabular}{lr}
\hline \hline Source & \multicolumn{1}{c}{$u_{i}$} \\
\hline Temperature & 0.0005 \\
Path length & 0.001 \\
Sample pressure & 0.001 \\
FTIR stability & 0.002 \\
Detector nonlinearity & 0.01 \\
\hline
\end{tabular}

For absorption coefficient values greater than $1 \times 10^{-4}$ $(\mu \mathrm{mol} / \mathrm{mol})^{-1} \mathrm{~m}^{-1}$, the average relative expanded uncer- tainty is $2.2 \%$. Plots of the absorption coefficient data for the compounds currently in the NIST Quantitative Infrared Database are shown in Appendix B. Data are shown for spectra at $0.125 \mathrm{~cm}^{-1}$ resolution with 3-term Blackman-Harris apodization. The data, at a number of resolutions and apodization functions, is available on compact disc in JCAMP-DX format with a viewer program. A digital signature accompanies each file, allowing users to ensure the integrity and source of the data file and traceability to NIST. Updates to the database are available over the internet.

\section{Appendix A. Compounds in the 1990 U.S.EPA Clean Air Act Amendment}

Table A1. List of the compounds in the 1990 U.S.EPA Clean Air Act amendment. Approximately 100 of these compounds have the vapor pressure required to prepare primary gas standards. The Chemical Abstracts Service Registry number is denoted by CAS No.

\begin{tabular}{|c|c|c|c|}
\hline CAS No. & Chemical name & CAS No. & Chemical name \\
\hline 75070 & Acetaldehyde & 67663 & Chloroform \\
\hline 60355 & Acetamide & 107302 & Chloromethyl methyl ether \\
\hline 75058 & Acetonitrile & 126998 & Chloroprene \\
\hline 98862 & Acetophenone & 1319773 & Cresols \\
\hline 53963 & 2-Acetylaminofluorene & 95487 & $o$-Cresol \\
\hline 107028 & Acrolein & 108394 & $m$-Cresol \\
\hline 79061 & Acrylamide & 106445 & $p$-Cresol \\
\hline 79107 & Acrylic acid & 98828 & Cumene \\
\hline 107131 & Acrylonitrile & 94757 & 2,4-D, salts and esters \\
\hline 107051 & Allyl chloride & 3547044 & DDE \\
\hline 92671 & 4-Aminobiphenyl & 334883 & Diazomethane \\
\hline 62533 & Aniline & 132649 & Dibenzofurans \\
\hline 90040 & $o$-Anisidine & 96128 & 1,2-Dibromo-3-chloropropane \\
\hline 1332214 & Asbestos & 84742 & Dibutylphthalate \\
\hline 71432 & Benzene & 106467 & 1,4-Dichlorobenzene(p) \\
\hline 92875 & Benzidine & 91941 & 3,3-Dichlorobenzidene \\
\hline 98077 & Benzotrichloride & 111444 & Dichloroethyl ether \\
\hline 100447 & Benzyl chloride & 542756 & 1,3-Dichloropropene \\
\hline 92524 & Biphenyl & 62737 & Dichlorvos \\
\hline 117817 & Bis(2-ethylhexyl) phthalate & 111422 & Diethanolamine \\
\hline 542881 & Bis(chloromethyl) ether & 121697 & N,N-Diethylaniline \\
\hline 75252 & Bromoform & 64675 & Diethyl sulfate \\
\hline 106990 & 1,3-Butadiene & 119904 & 3,3-Dimethoxybenzidine \\
\hline 156627 & Calcium cyanamide & 60117 & Dimethyl aminoazobenzene \\
\hline 105602 & Caprolactam & 119937 & 3,3-Dimethyl benzidine \\
\hline 133062 & Captan & 79447 & Dimethyl carbamoyl chloride \\
\hline 63252 & Carbaryl & 68122 & Dimethyl formamide \\
\hline 75150 & Carbon disulfide & 57147 & 1,1-Dimethyl hydrazine \\
\hline 56235 & Carbon tetrachloride & 131113 & Dimethyl phthalate \\
\hline 463581 & Carbonyl sulfide & 77781 & Dimethyl sulfate \\
\hline 120809 & Catechol & 534521 & 4,6-Dinitro- $O$-cresol \\
\hline 133904 & Chloramben & 51285 & 2,4-Dinitrophenol \\
\hline 57749 & Chlordane & 121142 & 2,4-Dinitrotoluene \\
\hline 7782505 & Chlorine & 13911 & 1,4-Dioxane \\
\hline 79118 & Chloroacetic acid & 122667 & 1,2-Diphenylhydrazine \\
\hline 532274 & 2-Chloroacetophenone & 106898 & Epichlorohydrin \\
\hline 106907 & Chlorobenzene & 106887 & 1,2-Epoxybutane \\
\hline 510156 & Chlorobenzilate & 140885 & Ethyl acrylate \\
\hline
\end{tabular}


Table A1. List of the compounds in the 1990 U.S.EPA Clean Air Act amendment. Approximately 100 of these compounds have the vapor pressure required to prepare primary gas standards. The Chemical Abstracts Service Registry number is denoted by CAS No. - Continued

\begin{tabular}{|c|c|c|c|}
\hline CAS No. & Chemical name & CAS No. & Chemical name \\
\hline 100414 & Ethyl benzene & 62759 & N-Nitrosodimethylamine \\
\hline 51796 & Ethyl carbamate & 59892 & N-Nitrosomorpholine \\
\hline 75003 & Ethyl chloride & 56382 & Parathion \\
\hline 106934 & Ethylene dibromide & 32688 & Pentachloronitrobenzene \\
\hline 107062 & Ethylene dichloride & 87865 & Pentachlorophenol \\
\hline 107211 & Ethylene glycol & 108952 & Phenol \\
\hline 151564 & Ethylene imine & 106503 & $p$-Phenylenediamine \\
\hline 75218 & Ethylene oxide & 75445 & Phosgene \\
\hline 96457 & Ethylene thiourea & 803512 & Phosphine \\
\hline 75343 & Ethylidene dichloride & 723140 & Phosphorus \\
\hline 50000 & Formaldehyde & 85449 & Phthalic anhydride \\
\hline 76448 & Heptachlor & 1336363 & Polychorinated biphenyls \\
\hline 118741 & Hexachlorobenzene & 1120714 & 1,3-Propane sulfone \\
\hline 87683 & Hexachlorobutadiene & 57578 & Beta-Propiolactone \\
\hline 77474 & Hexachlorocylcopentadiene & 123386 & Propionaldehyde \\
\hline 67721 & Hexachloroethane & 114261 & Propoxur \\
\hline 822060 & Heamethylene-1,6-diisocyanate & 78875 & Propylene dichloride \\
\hline 680319 & Hexamethylphosphoramide & 75569 & Propylene oxide \\
\hline 110543 & Hexane & 75558 & 1,2-Propylenimine \\
\hline 302012 & Hydrazine & 91225 & Quinoline \\
\hline 7647010 & Hydrochloric acid & 106514 & Quinone \\
\hline 7664393 & Hydrogen fluoride & 100425 & Styrene \\
\hline 123319 & Hydroquinone & 96093 & Styrene oxide \\
\hline 78591 & Isophorone & 1746016 & $\begin{array}{l}2,3,7,8 \text {-Tetrachlorodibenzo } \\
p \text {-dioxin }\end{array}$ \\
\hline 58899 & Lindane & 79345 & $1,1,2,2$-Tetrachloroethane \\
\hline 108316 & Maleic anhydride & 127184 & Tetrachloroethylene \\
\hline 67561 & Methanol & 7550450 & Titanium tetrachloride \\
\hline 72435 & Methoxychlor & 108883 & Toluene \\
\hline 74839 & Methyl bromide & 95807 & 2,4-Toluene diamine \\
\hline 74873 & Methyl chloride & 584849 & 2,4-Toulene diisocyanate \\
\hline 71556 & Methyl chloroform & 95534 & $o$-Toluidine \\
\hline 78933 & Methyl ethyl ketone & 800135 & Toxaphene \\
\hline 60344 & Methyl hydrazine & 120821 & 1,2,4-Tricholorobenzene \\
\hline 74884 & Methyl iodide & 79005 & 1,1,2-Trichloroethane \\
\hline 108101 & Methyl isobutyl ketone & 79016 & Trichloroethylene \\
\hline 624839 & Methyl isocyanate & 95954 & 2,4,5-Trichlorophenol \\
\hline 80626 & Methyl methacrylate & 88062 & 2,4,6-Trichlorophenol \\
\hline 1634044 & Methyl tert butyl ether & 121448 & Triethylamine \\
\hline 101144 & 4,4-Methylene bis(2-chloroaniline) & 1582098 & Trifluralin \\
\hline 75092 & Methylene chloride & 540841 & 2,2,4-Trimethylpentane \\
\hline 101688 & Methylene diphenyl & 108054 & Vinyl acetate \\
\hline 101779 & 4,4-Methylenedianiline & 593602 & Vinyl bromide \\
\hline 91203 & Naphthalene & 75014 & Vinyl chloride \\
\hline 98953 & Nitrobenzene & 75354 & Vinylindene chloride \\
\hline 92933 & 4-Nitrobiphenyl & 1330207 & Xylenes \\
\hline 100027 & 4-Nitrophenol & 95476 & $o$-xylene \\
\hline 79469 & 2-Nitropropane & 108383 & $m$-xylene \\
\hline 684935 & N-Nitroso-N-methylurea & 106423 & $p$-xylene \\
\hline
\end{tabular}




\section{Appendix B. Absorption Coefficient Data}

The following figures, Fig. B1 through B21, show the absorption coefficient data for compounds currently in the NIST Quantitative Infrared Database, SRD 79. In all cases the data represent spectra at $0.125 \mathrm{~cm}^{-1}$ resolution with 3-term Blackman-Harris apodization. In all cases, the absorbance was defined as $-\log _{10}\left(I / I_{0}\right)$.

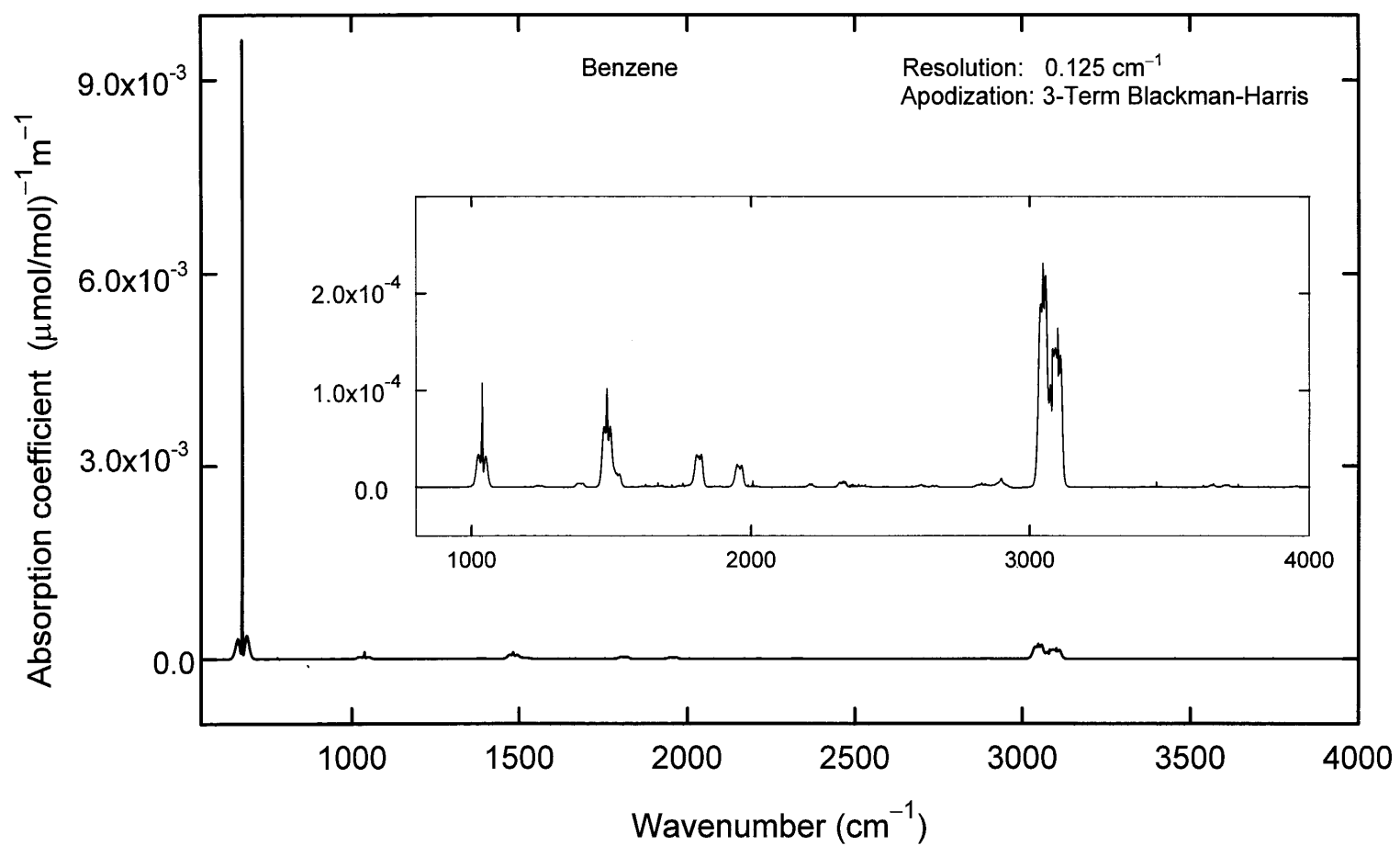

Fig. B1. Benzene.

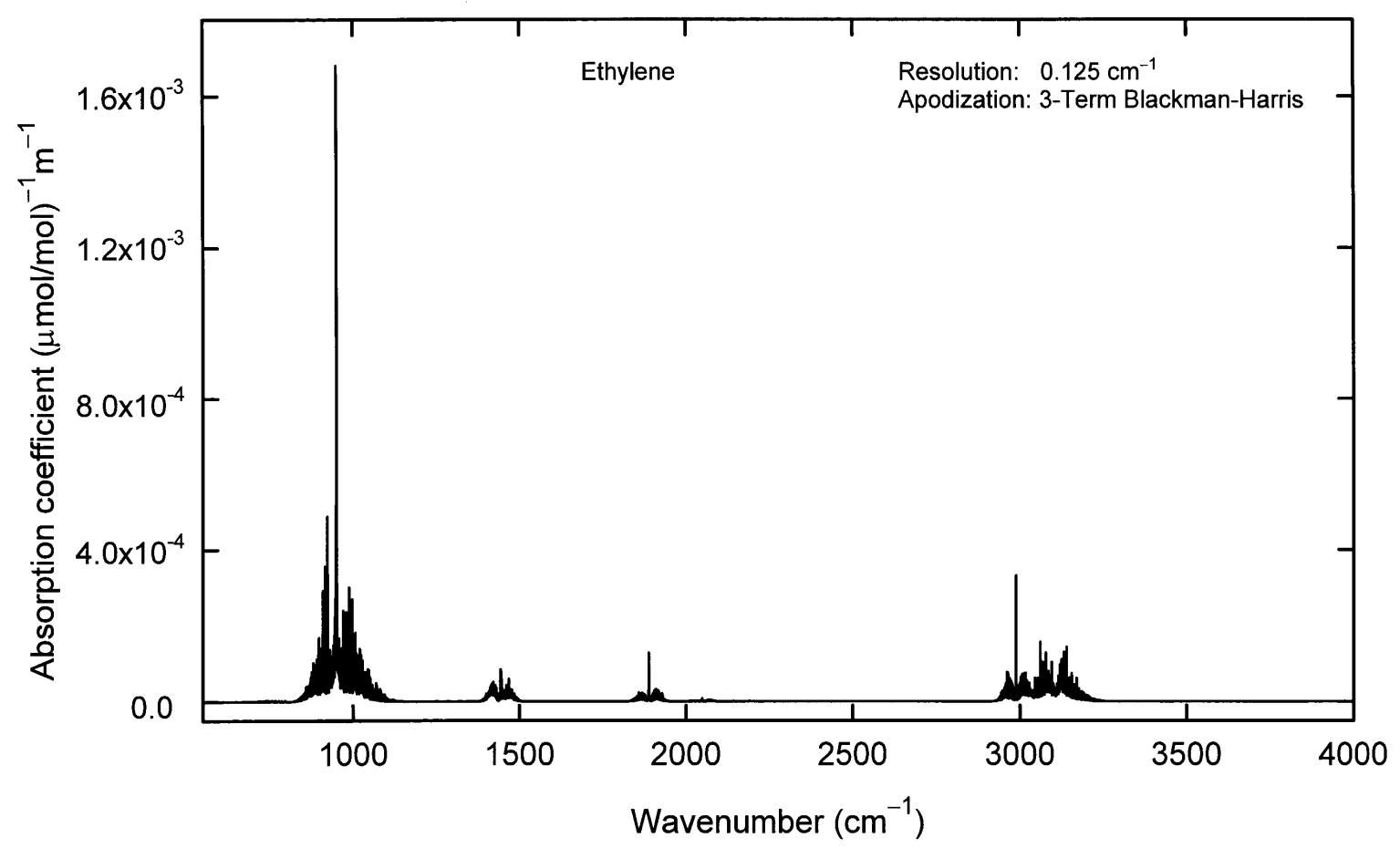

Fig. B2. Ethylene. 
Journal of Research of the National Institute of Standards and Technology

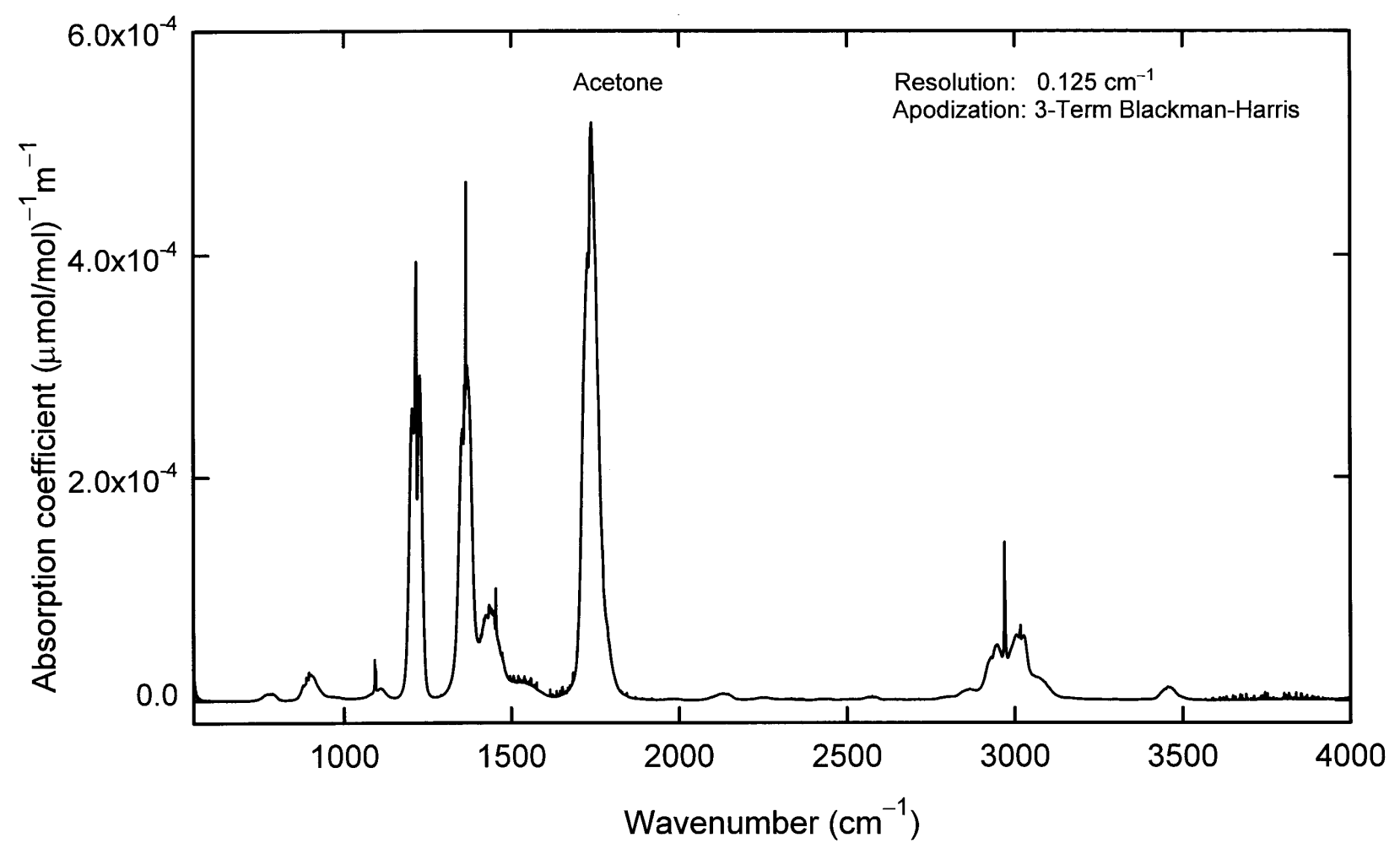

Fig. 3. Acetone.

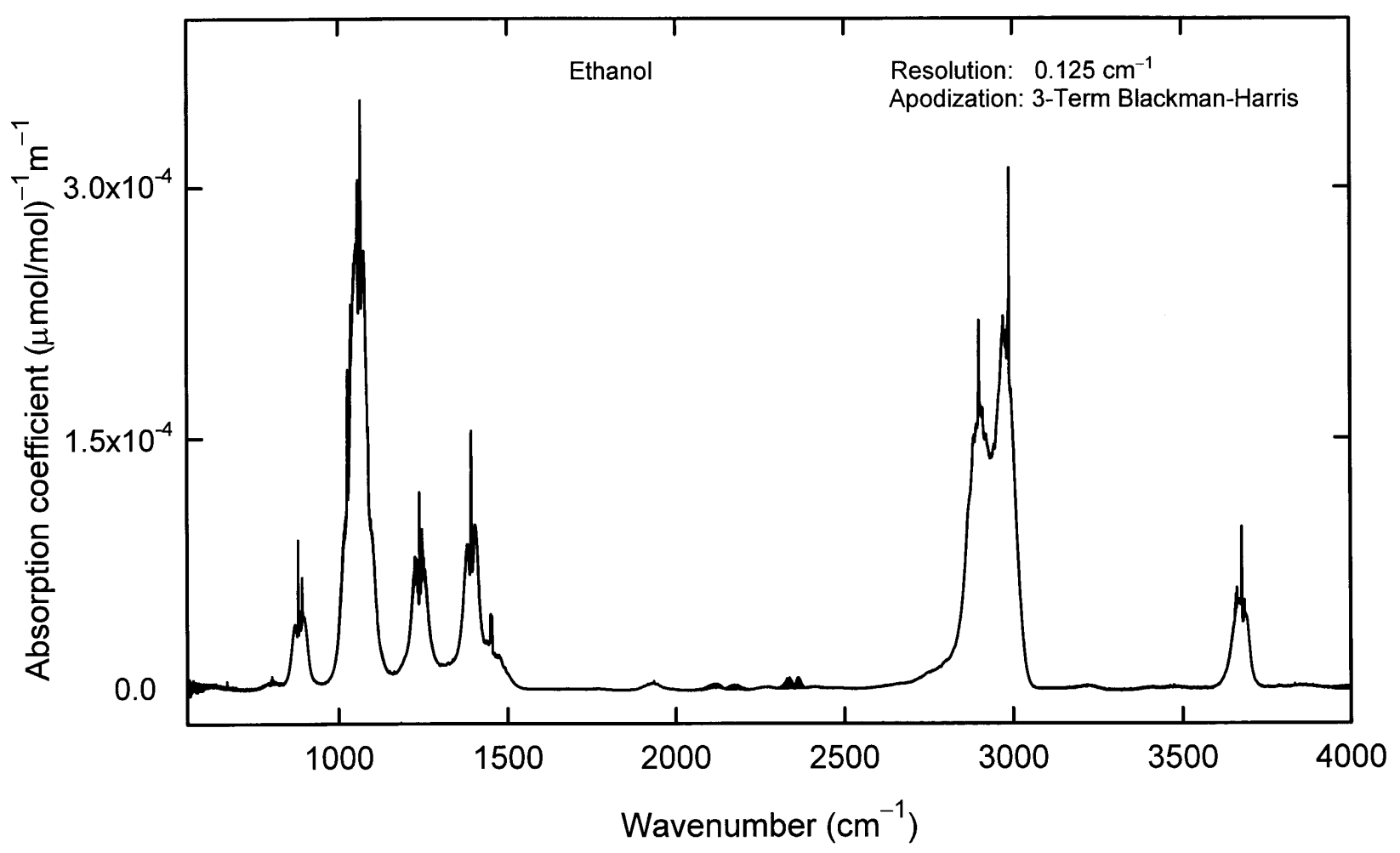

Fig. B4. Ethanol. 
Journal of Research of the National Institute of Standards and Technology

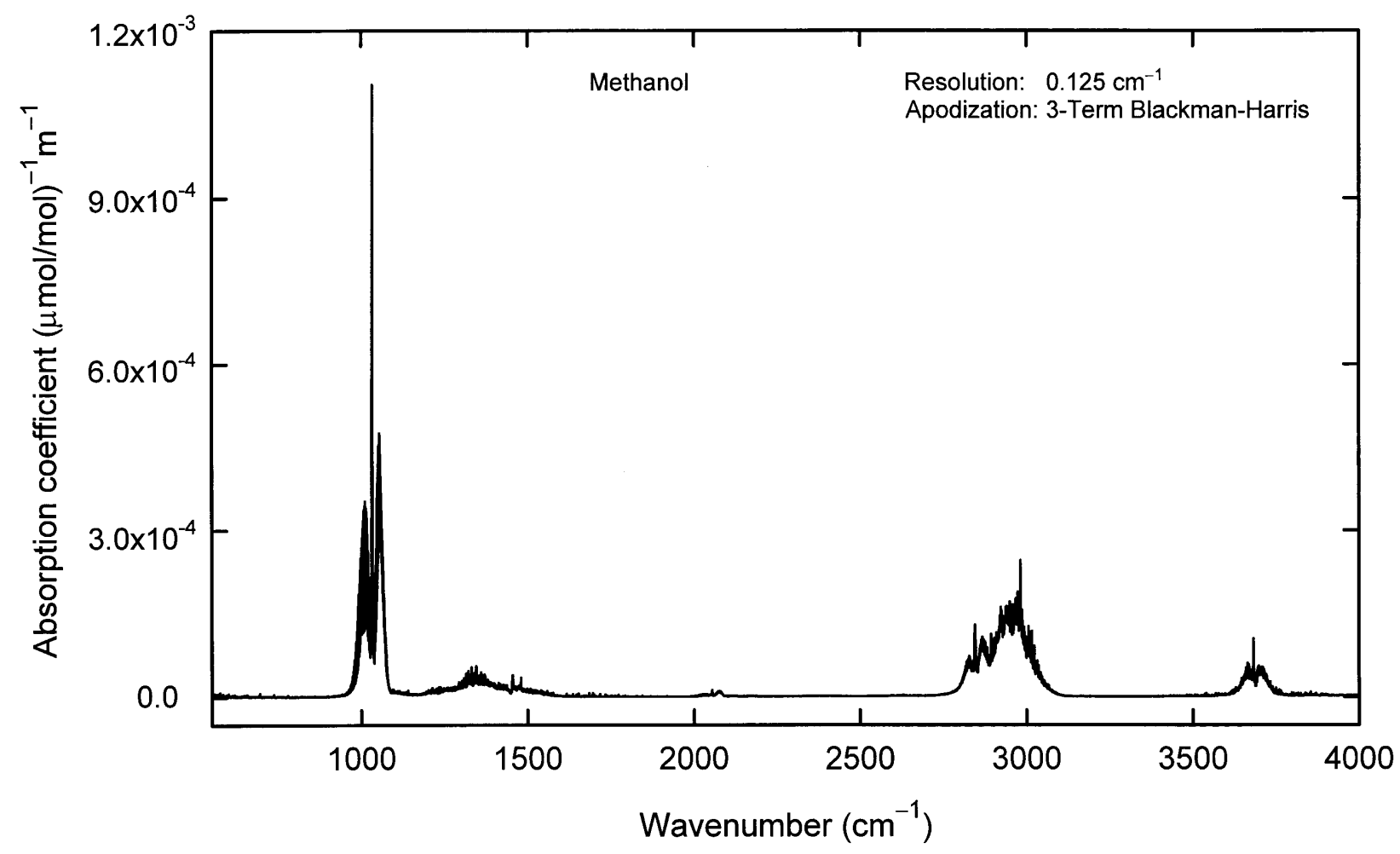

Fig. B5. Methanol.

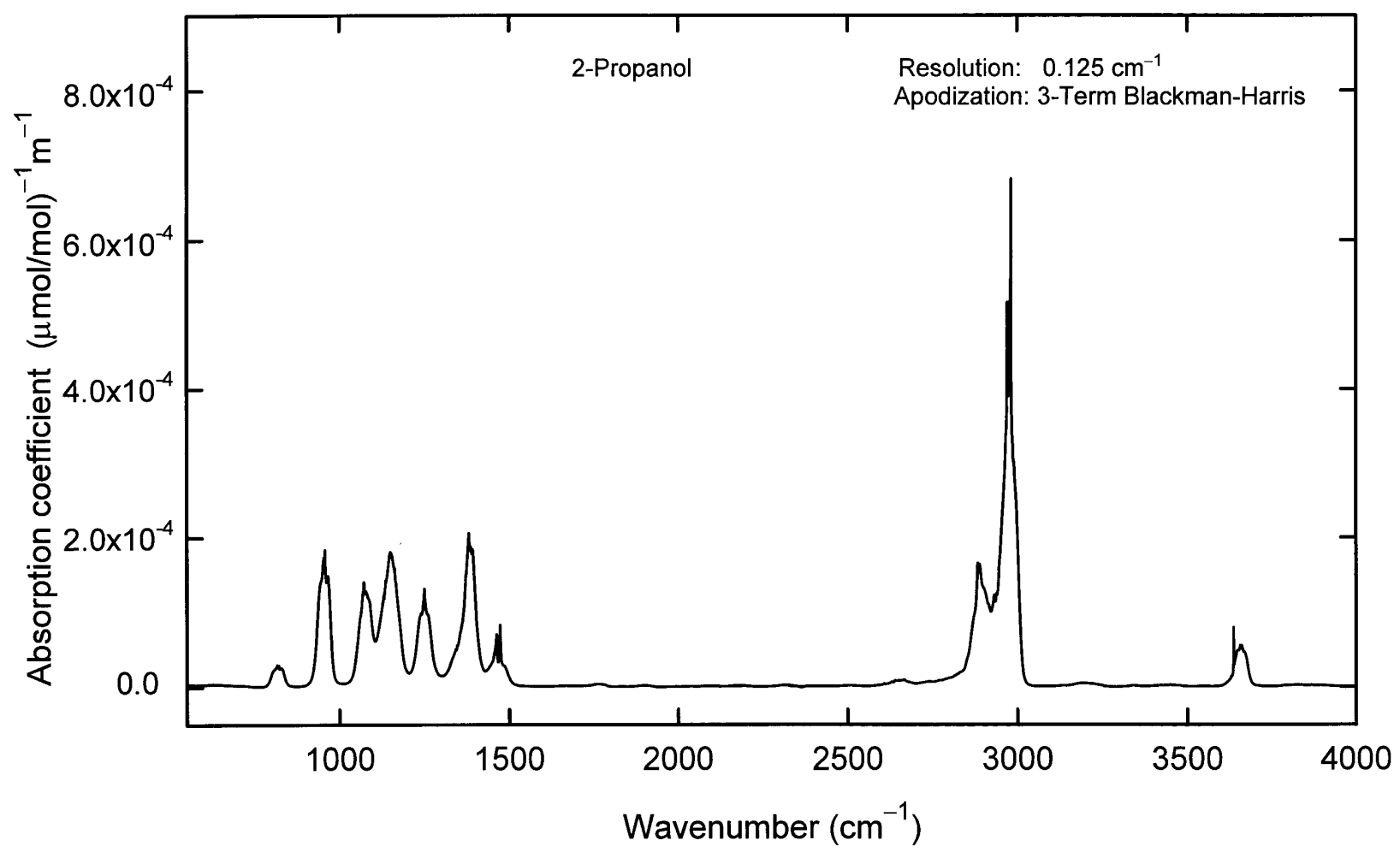

Fig. B6. 2-Propanol. 
Journal of Research of the National Institute of Standards and Technology

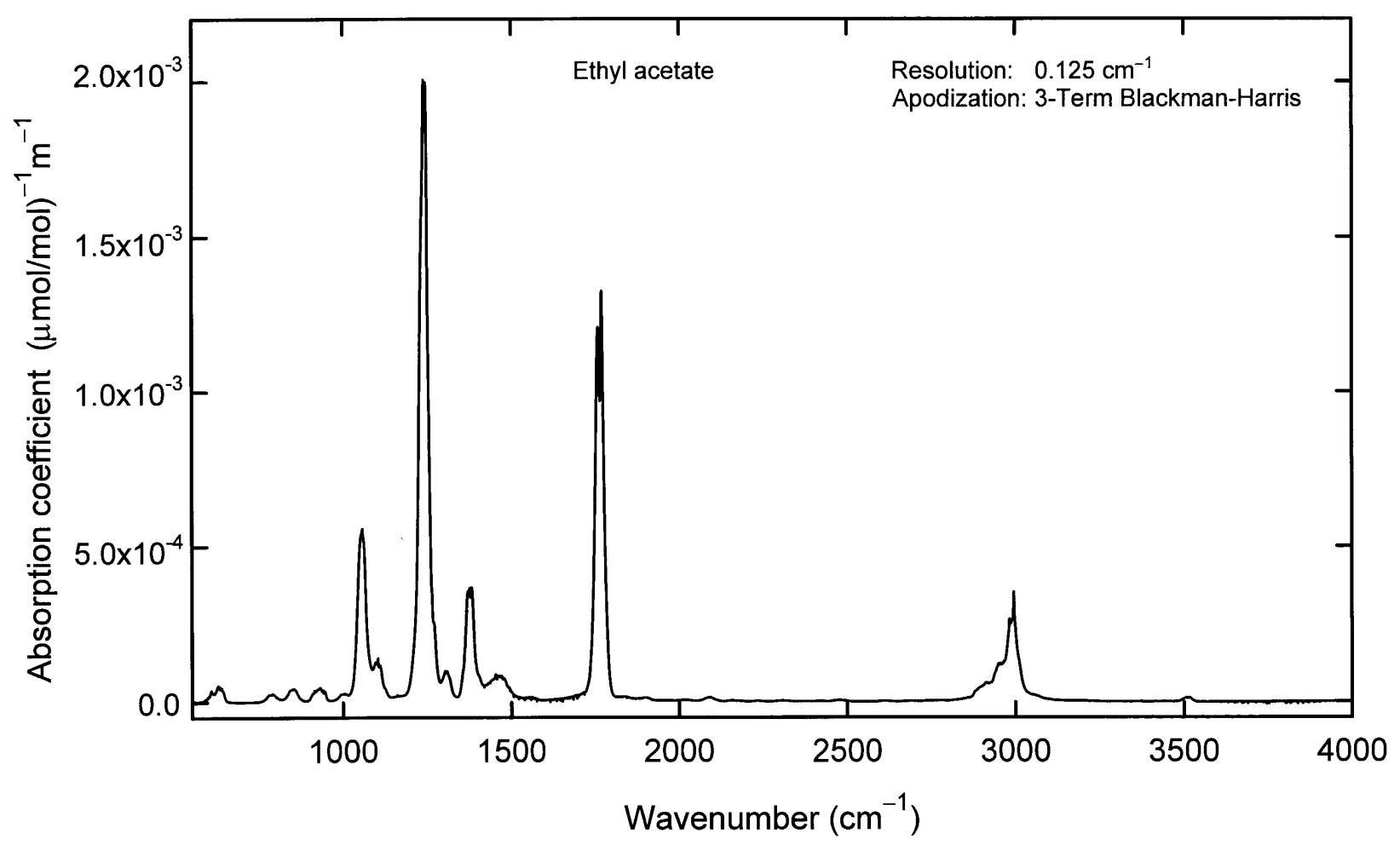

Fig. B7. Ethyl acetate.

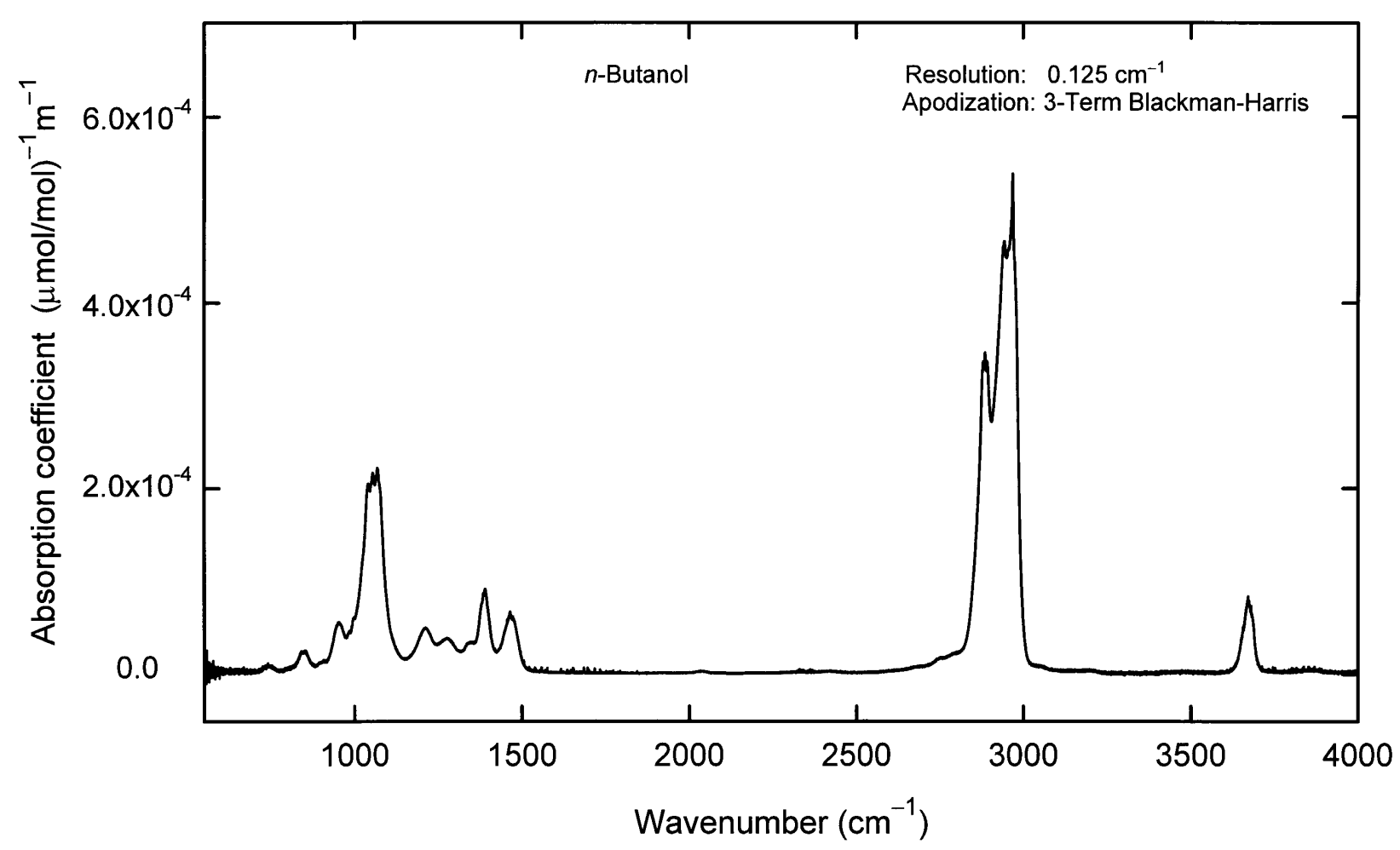

Fig. B8. $n$-Butanol. 
Journal of Research of the National Institute of Standards and Technology

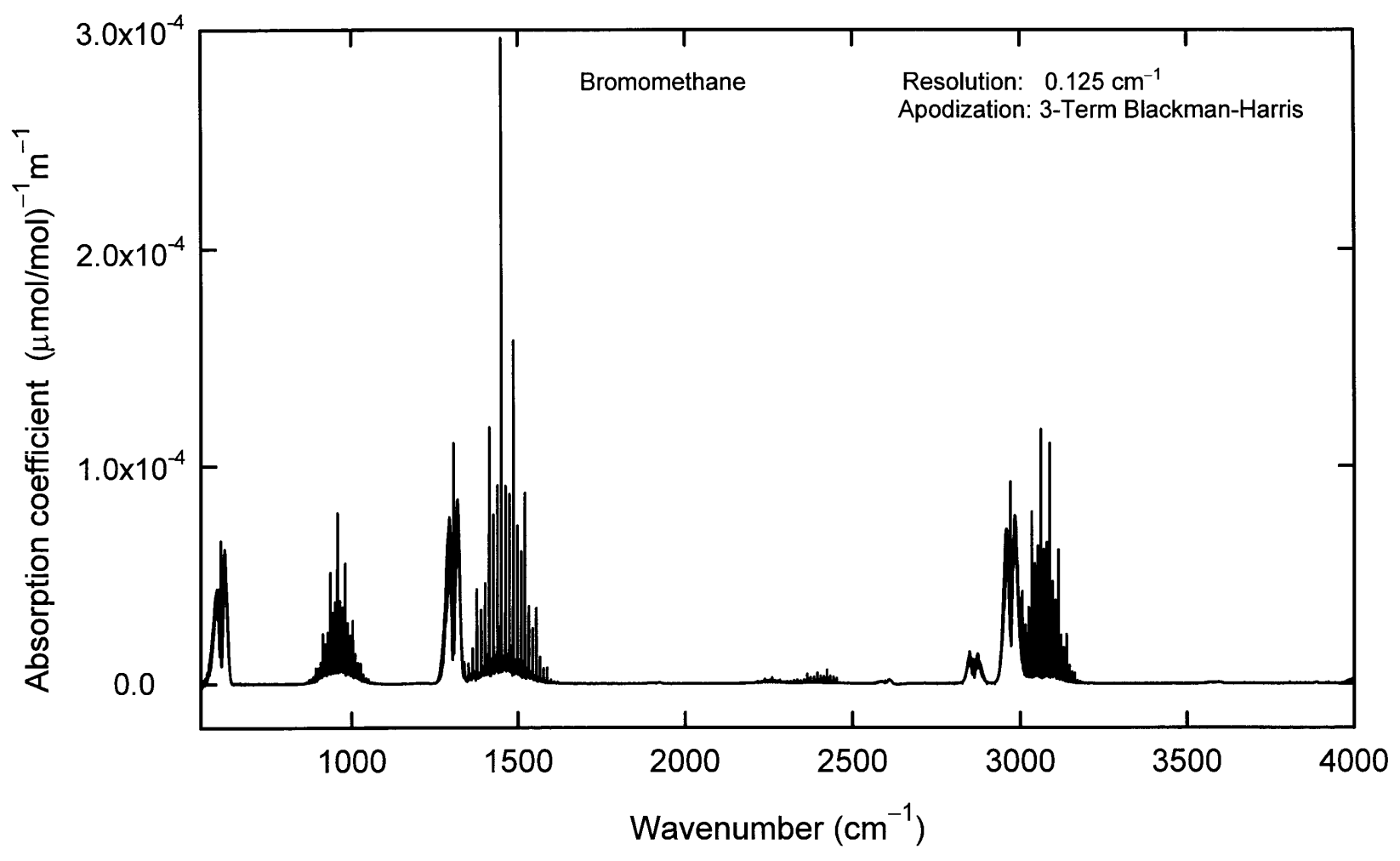

Fig. B9. Bromomethane.

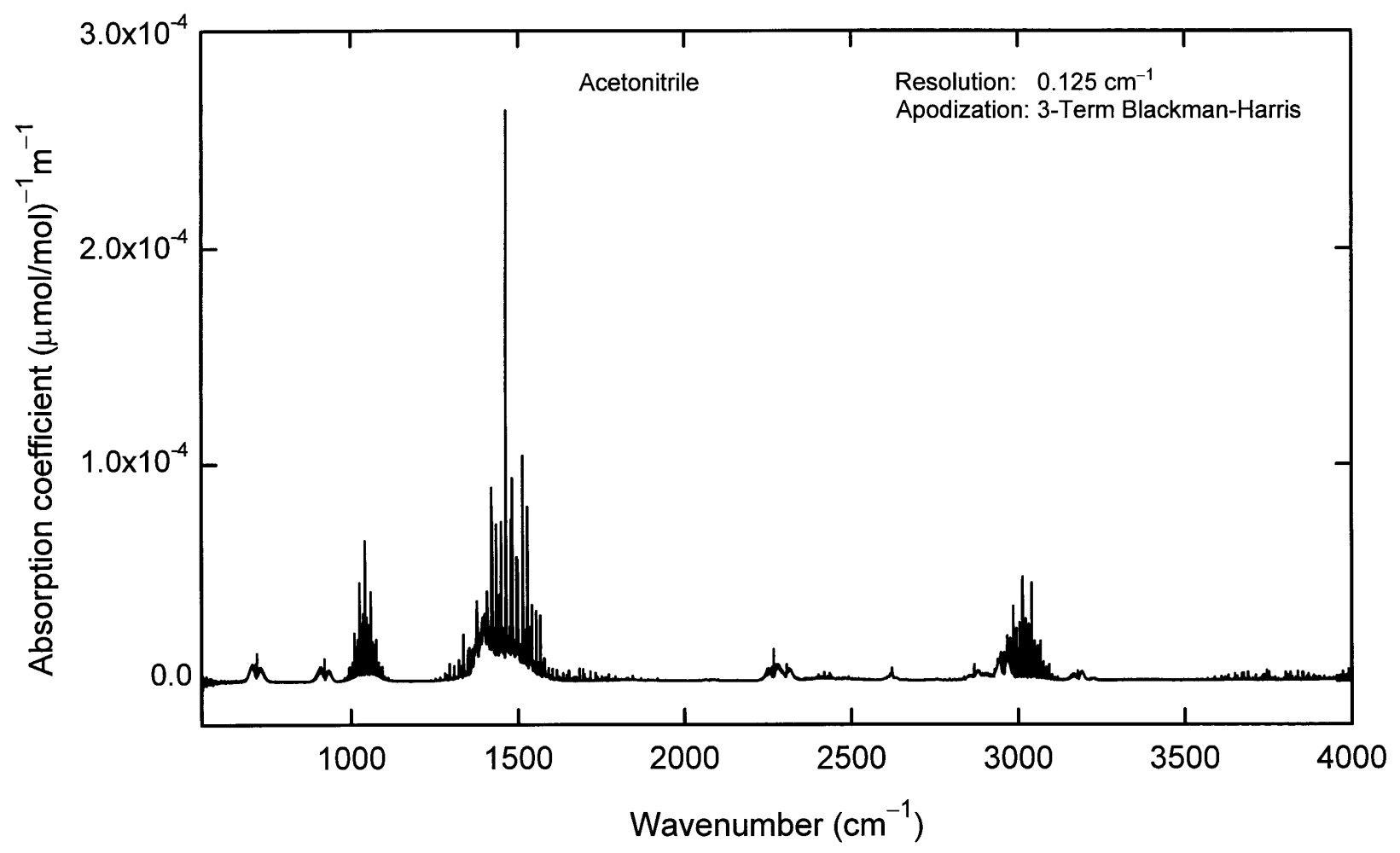

Fig. B10. Acetonitrile. 


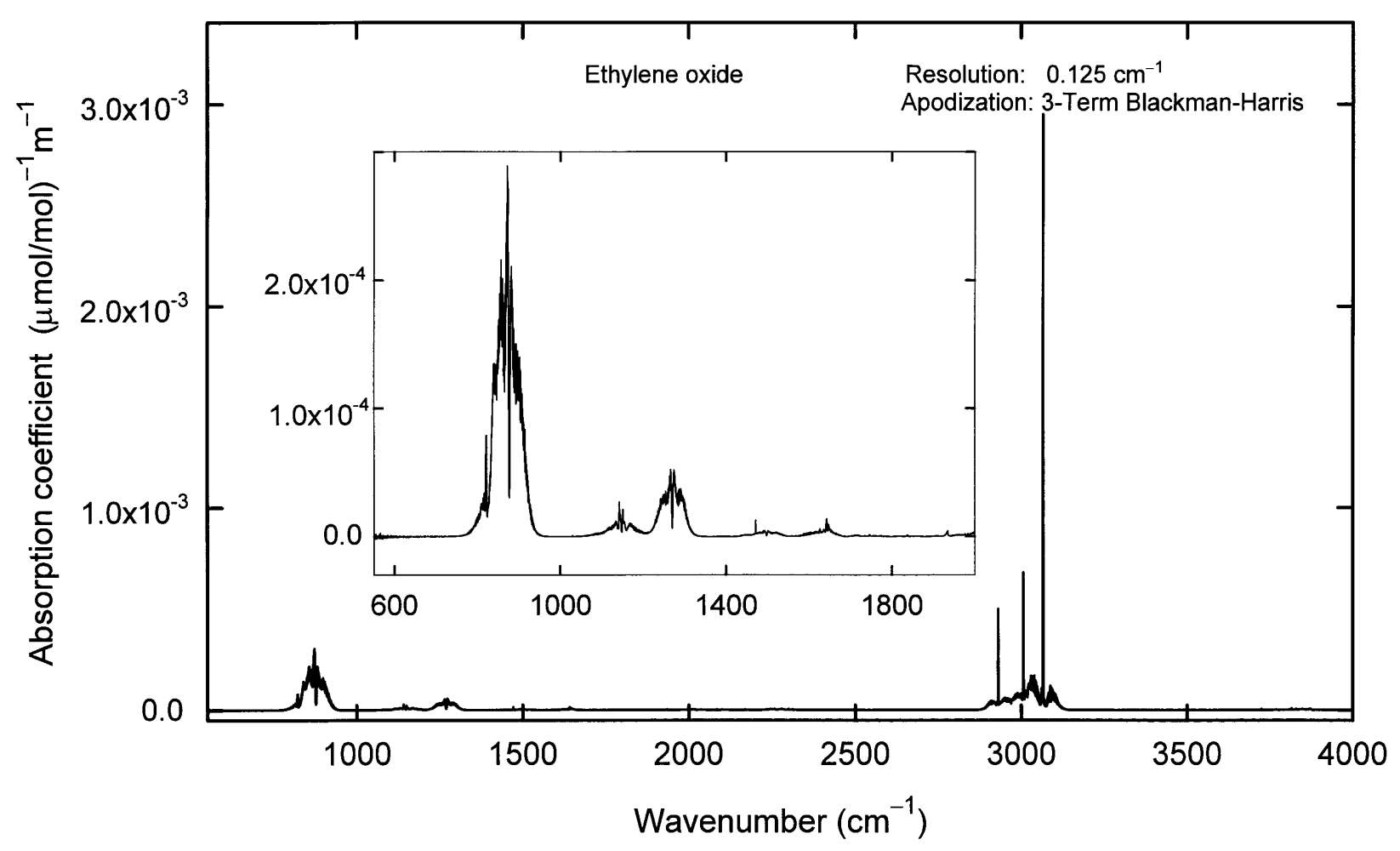

Fig. B11. Ethylene oxide.

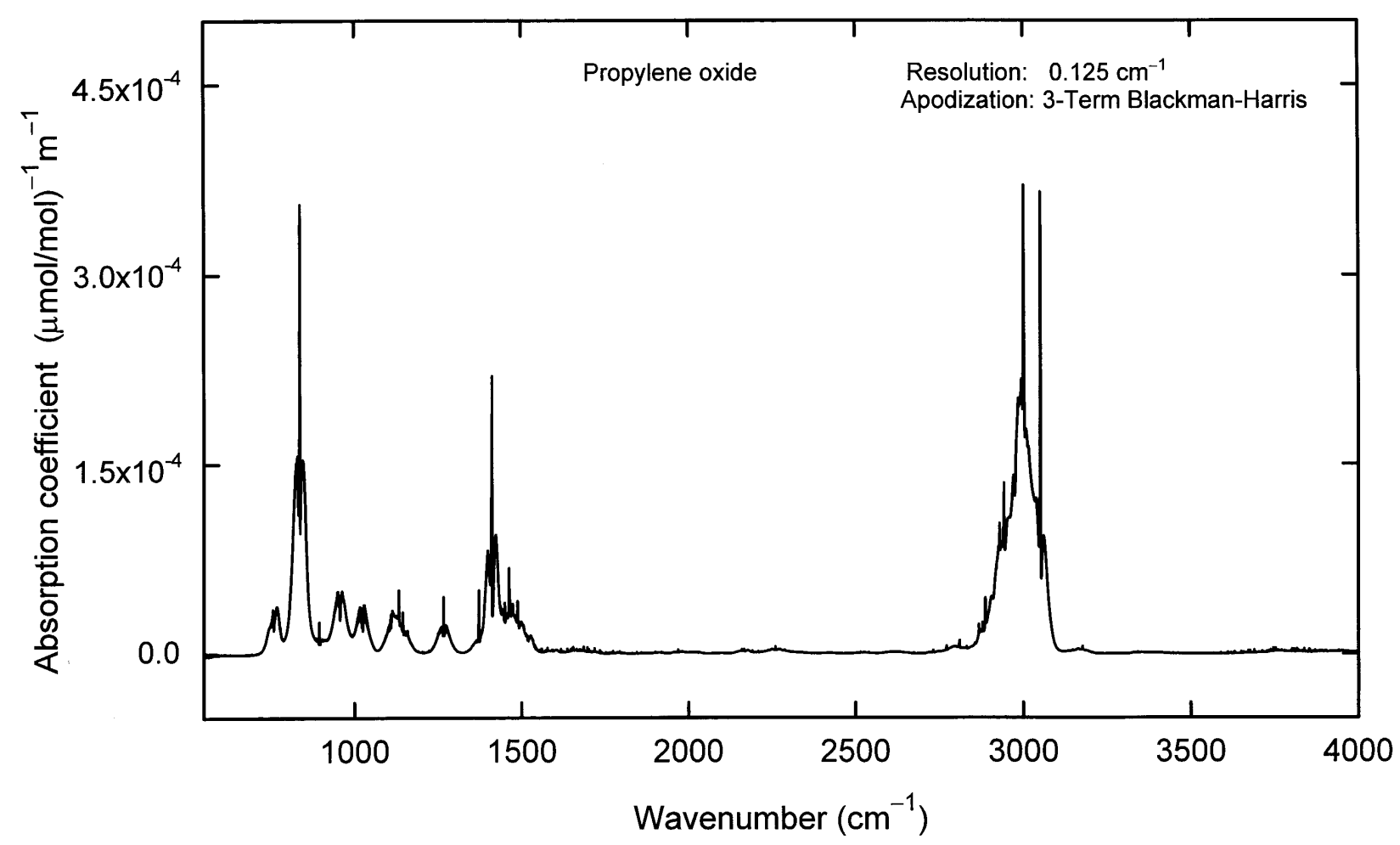

Fig. B12. Propylene oxide. 


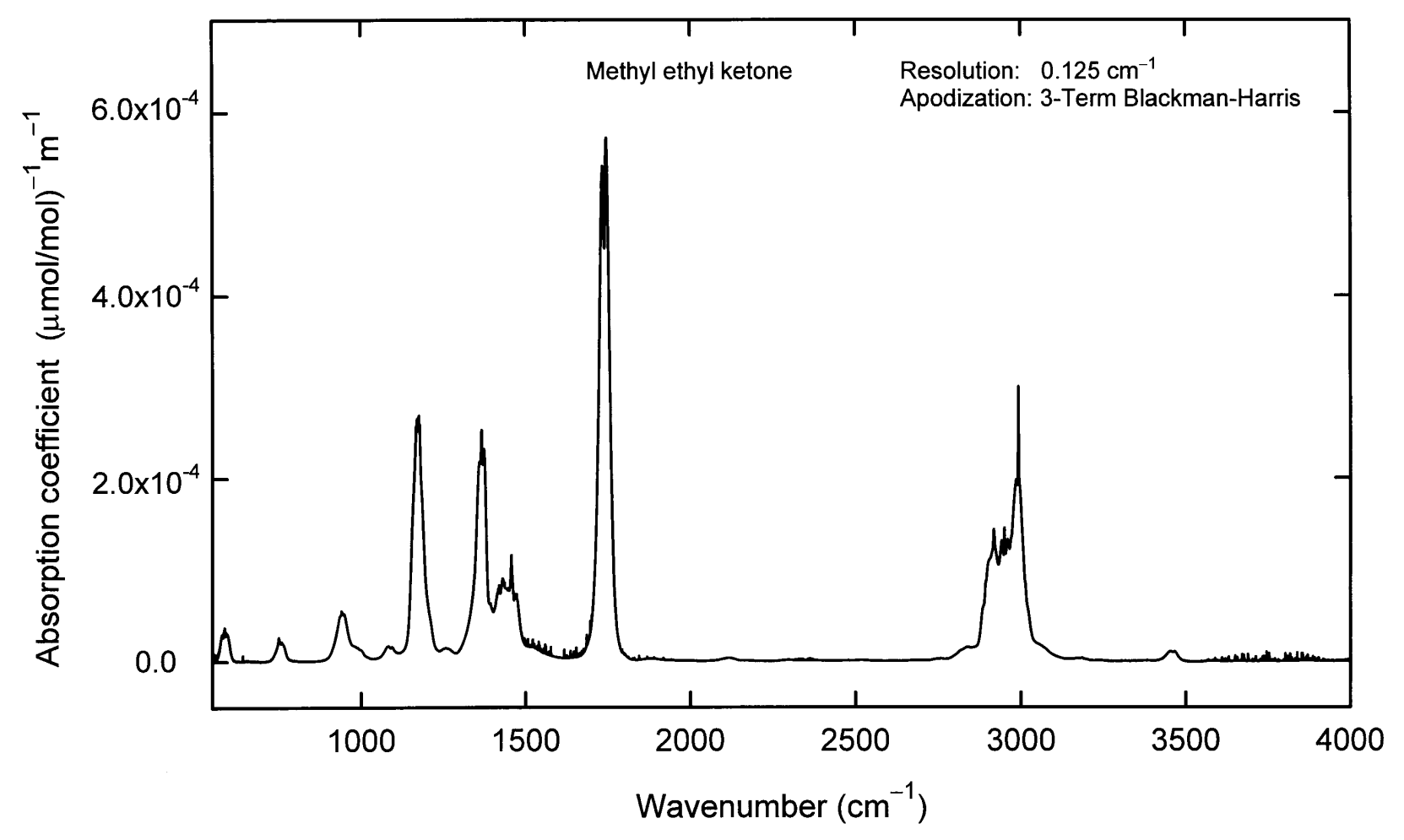

Fig. B13. Methyl ethyl ketone.

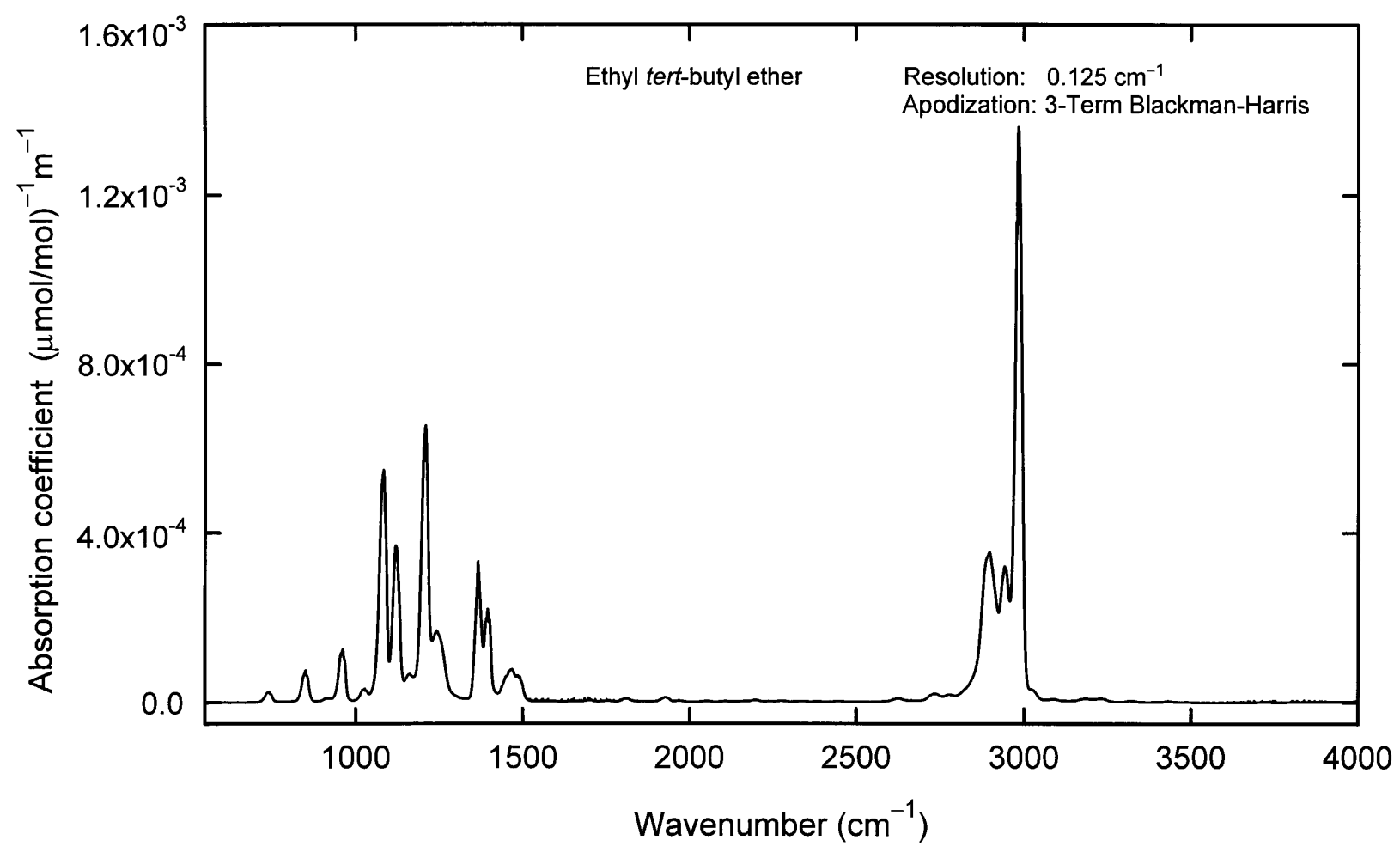

Fig. B14. Ethyl tert-butyl ether. 


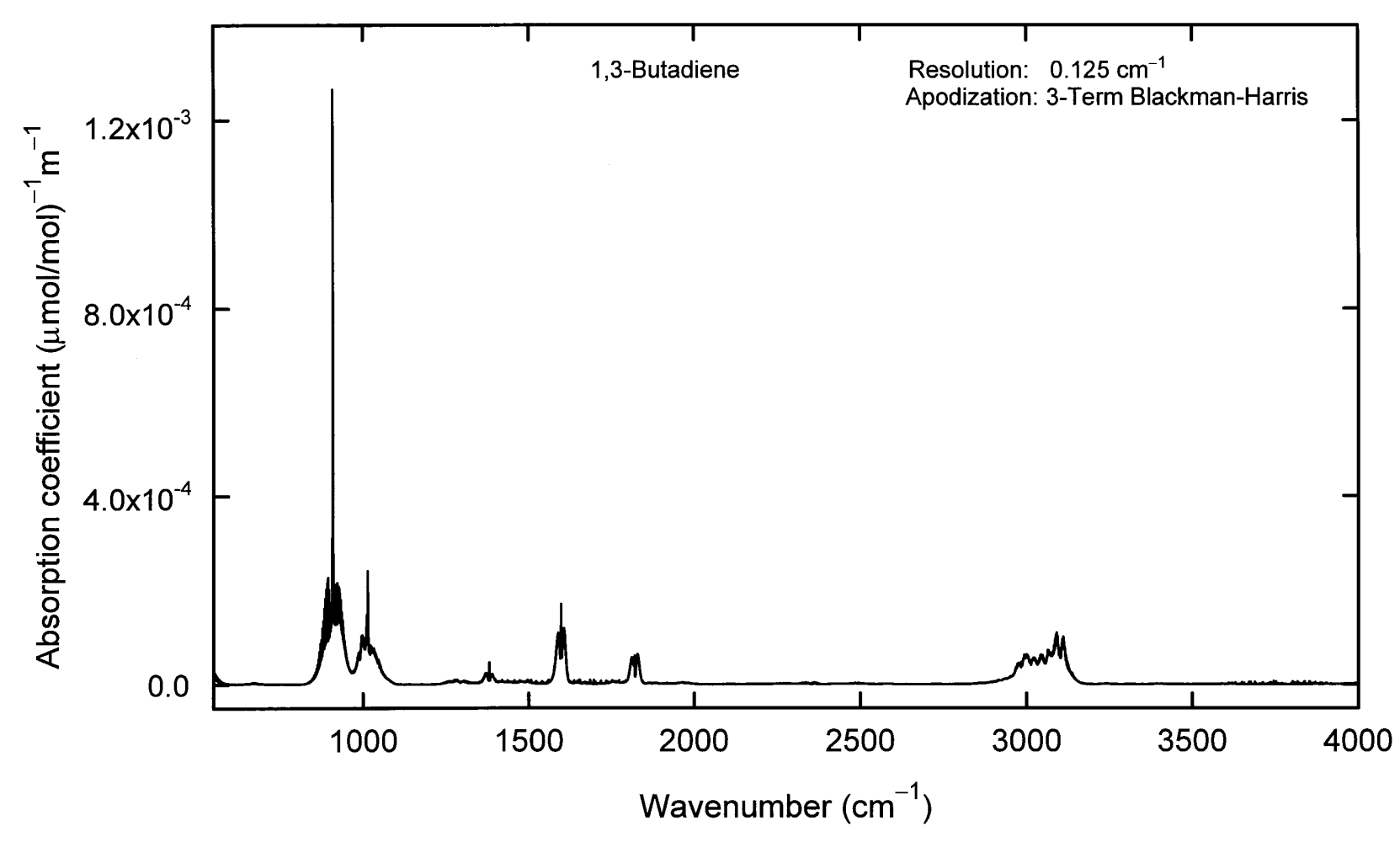

Fig. B15. 1,3-Butadiene.

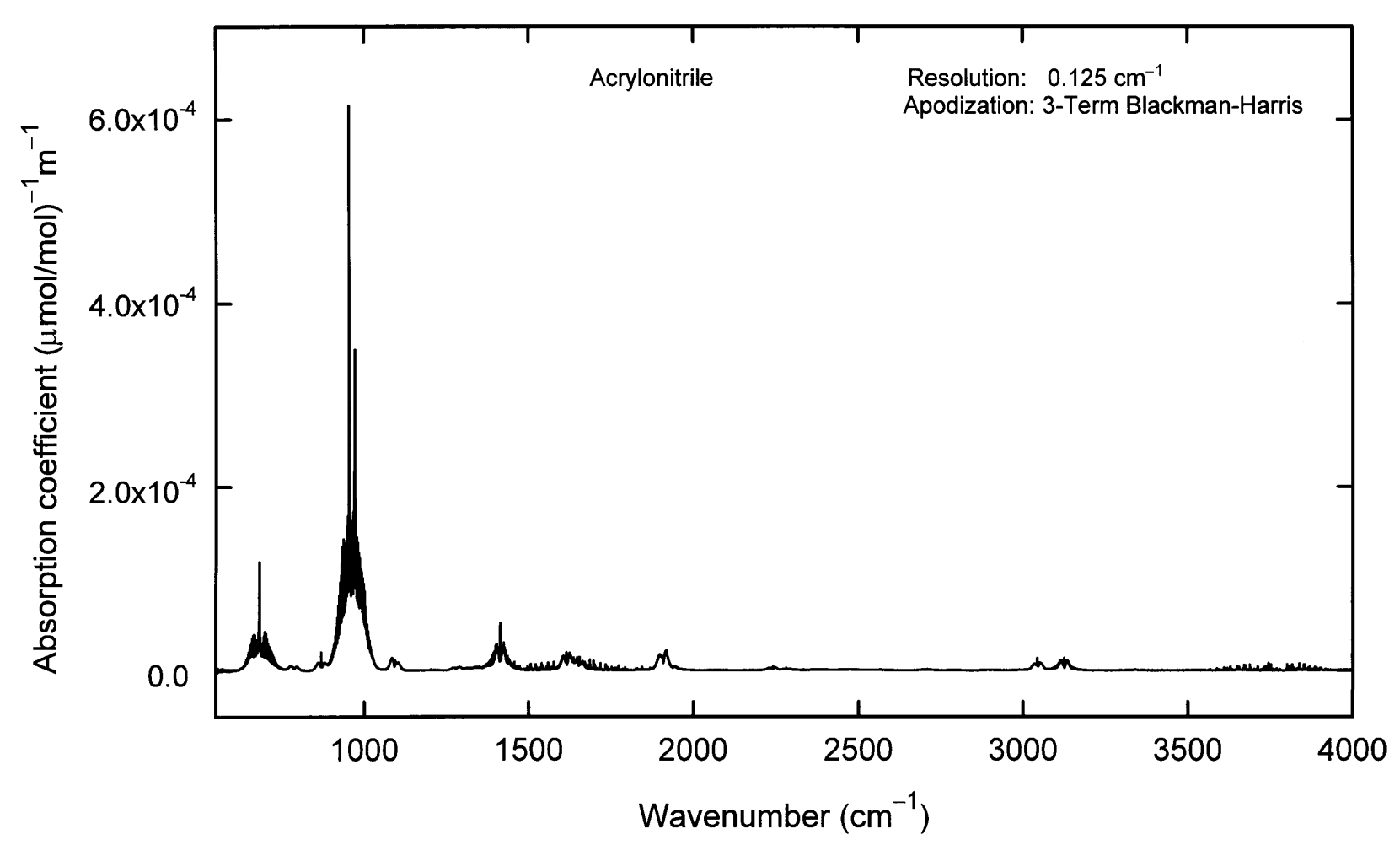

Fig. B16. Acrylonitrile. 
Journal of Research of the National Institute of Standards and Technology

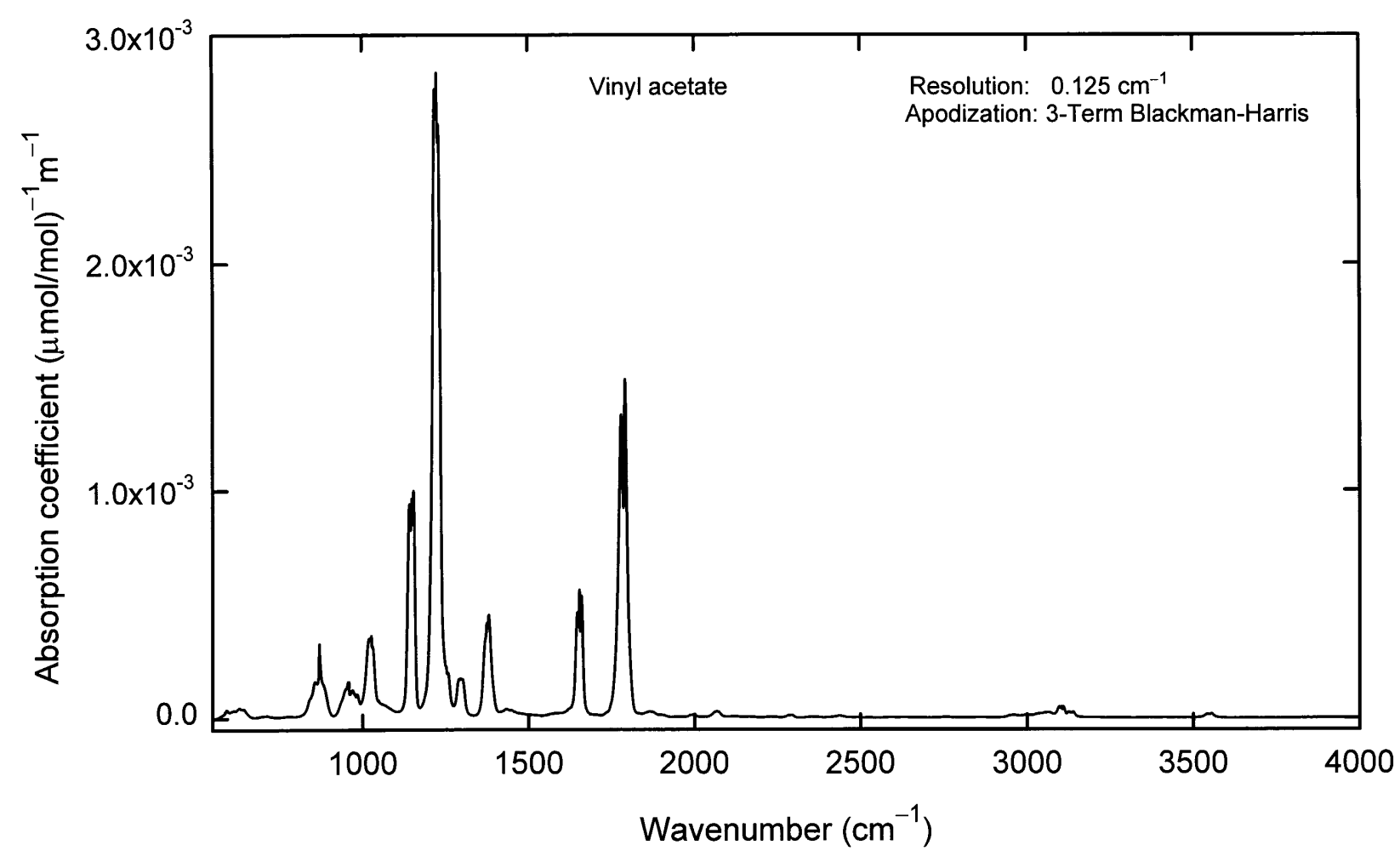

Fig. B17. Vinyl acetate.

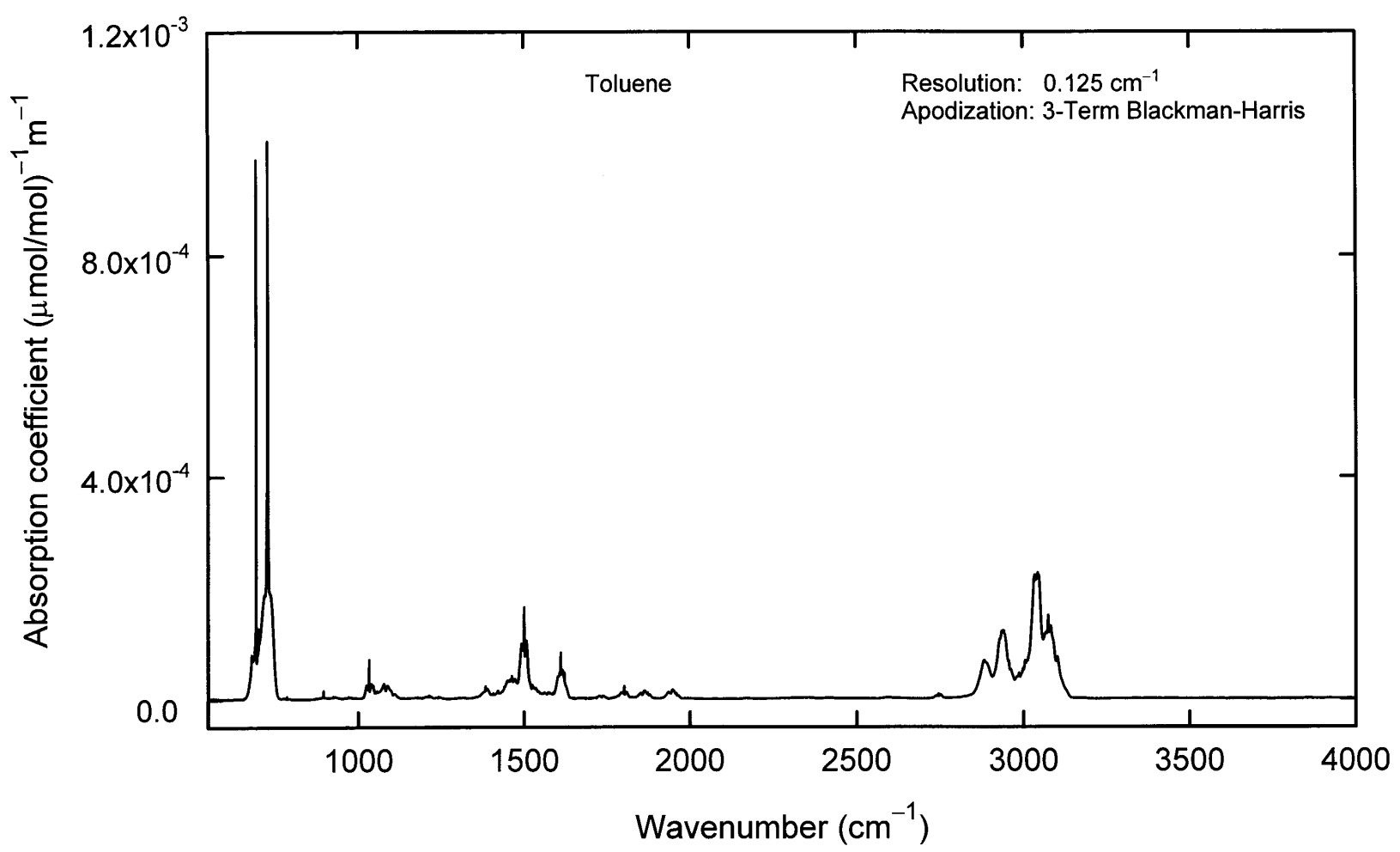

Fig. B18. Toluene. 
Journal of Research of the National Institute of Standards and Technology

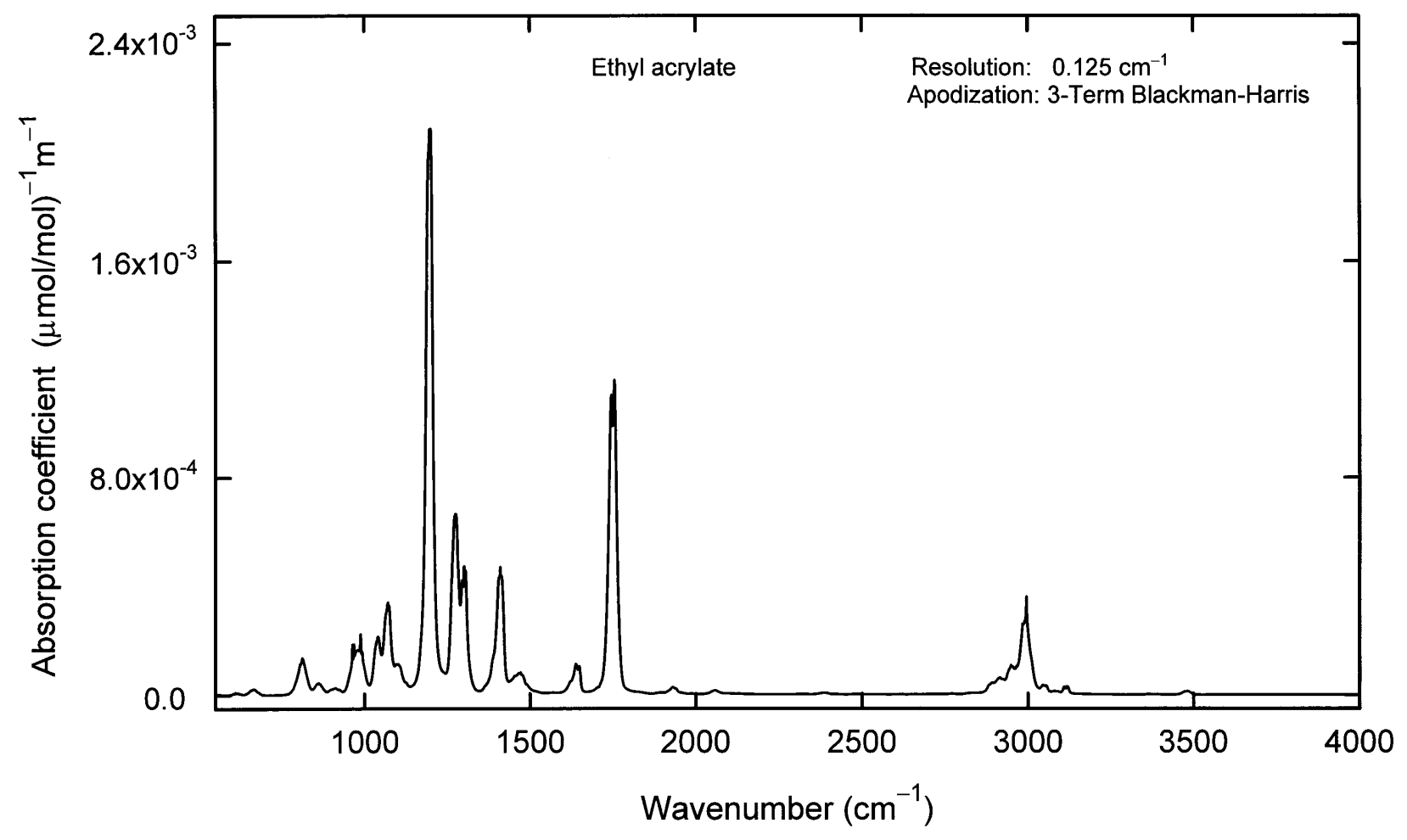

Fig. B19. Ethyl acrylate.

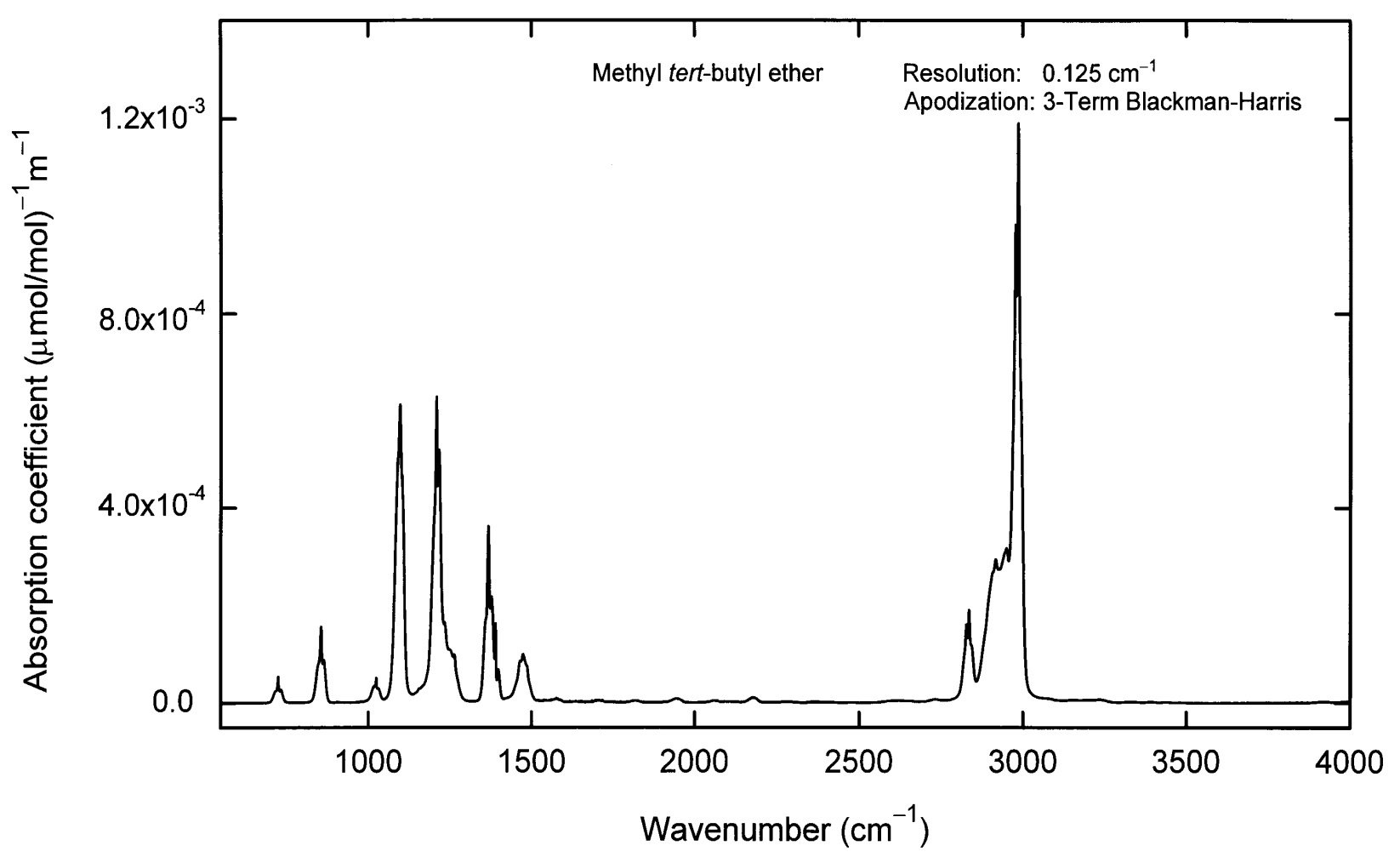

Fig. B20. Methyl tert-butyl ether. 


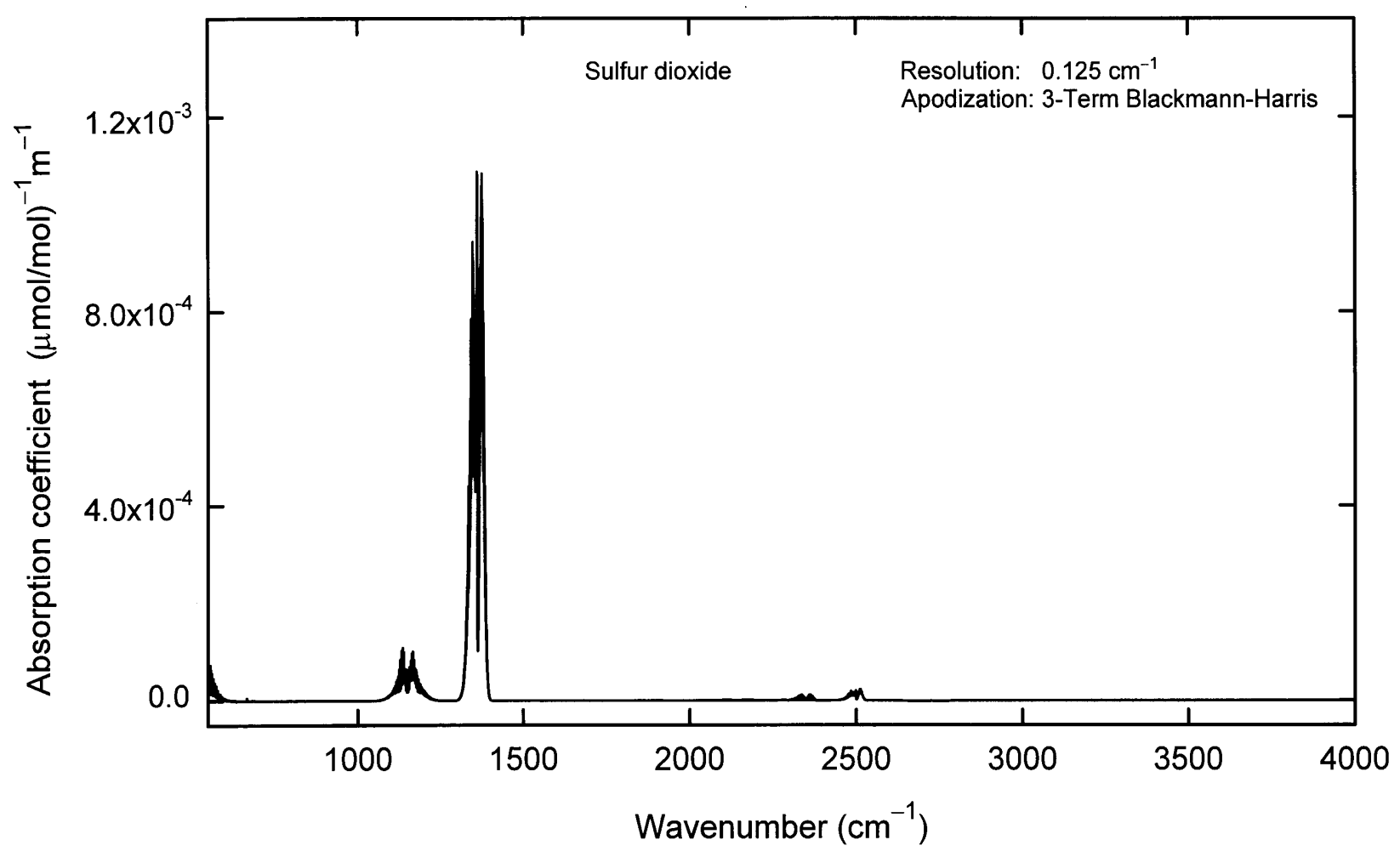

Fig. B21. Sulfur dioxide.

\section{Acknowledgments}

The authors wish to thank S. J. Wetzel, D. vanVlack, and C. L. Calhoun for their help with the FTIR data acquisition and anlaysis and C. Mack and S. Margolis for the analysis of the pure VOCs. Additionally, the authors would like to thank J. C. Travis, B. Phillips, G. Russwurm, W. Bell, P. Woods, P. Hanst, W. Herget, R. Kagann, R. Richardson, and P. Griffiths for many helpful discussions regarding this work.

\section{References}

[1] C. Henry, Analytical Chemistry News \& Features, April 1, 1998, p. 273 A.

[2] (Proposed) Test Method 320 Measurement of Vapor Phase Organic and Inorganic Emissions by Extractive Fourier Transform Infrared Spectroscopy, Federal Register, Part 63, Appendix A.

[3] Compendium Method TO-16, Long-Path Open-Path Fourier Transform Infrared Monitoring of Atmospheric Gases, EPA Contract 68-D5-0049, NERL, U.S.EPA, Research Triangle Park, NC.

[4] Federal Clean Air Act, Title II, Public Law 101-549.

[5] R. L. Richardson, Jr. and P. R. Griffiths, Appl. Spectros. 52, 143-153 (1998).
[6] Quantitative Infrared Vapor Phase Spectra, Contract No. 68D90055 (U.S. Environmental Protection Agency, Emission Measurement Branch, Research Triangle Park, North Carolina).

[7] Rothman L. S., Rinsland C. P., Goldman A, Massie S. T., Edwards D. P., Flaud J.-M., Perrin, A., Camy-Peyret C., Dana V., Mandin J.-Y., Schroeder J, McCann A., Gamache R. R., Wattson R. B., Yoshino K., Chance K. V., Jucks, K. W., Brown, L. R., Nemtchinov V., Varanasi, P. 1998 The HITRAN Molecular Spectroscopic Database and HAWKS (HITRAN Atmospheric Workstation): 1996 Edition Journal of Quantitative Spectroscopy and Radiative Transfer 60 (in press). See also Phillips Laboratory/Geophysics Directorante, Hanscom AFB, MA; http:/www. HITRAN. com.

[8] P. L. Hanst and S. T. Hanst, Infrared Spectra for Quantitative Analysis of Gases Infrared Analysis, Inc., Anaheim, CA (1996).

[9] Gas Phase Infrared Spectral Standards, MIDAC Corporation, Irvine, CA 92614.

[10] J. F. Sprouse, Quantitative Infrared Spectral Database, Sprouse Scientific Systems, Charlotte, North Carolina (1991).

[11] R. S. McDonald and P. A. Wilks, Jr. Appl. Spectros. 42, 151162 (1988).

[12] P. M. Chu, G. C. Rhoderick, W. J. Lafferty, and F. R. Guenther, Proceedings of the Air \& Waste Management Association, 89th Annual Meeting and Exhibition, Nashville, Tennessee (1996). See also, W. P Schmidt and H. L Rook, Anal. Chem. 55, 290-294 (1983); G. C. Rhoderick and W. L. Zielinski, Anal. Chem. 60, 2454-2466 (1988); G. C. Rhoderick Fresenius, J. Anal. Chem. 341, 521-531 (1991). 
[13] R. L. Sams, private communication.

[14] W. J. Lafferty and A. S. Pine, G. Hilpert, R. L. Sams, and J.-M. Flaud, J. Mol. Spectros. 176, 280-286 (1996).

[15] W. J. Lafferty, R. L. Sams, and J. M. Flaud, 88th Annual Meeting of the Air and Waste Management Association, San Antonio, Texas (1995).

[16] R. A. Toth, J. Opt. Soc. Am. B 8, 2236-2255 (1991). R. A. Toth, J. Opt. Soc. Am B, 10, 2006-2029 (1993). [17] P. R. Griffiths, J. A. deHaseth, Fourier Transform Infrared Spectrometry, John Wiley \& Sons, Inc., New York (1986).

[18] OPUS 2.2, Bruker Instruments, Billerica, MA 01821.

[19] Deresolve, W. J. Phillips and Arnold Engineering Development Center, TN 37389-4300. See also see http://www. epa. gov/ttn/ emc/ftir/deresolv. html.

[20] Guide to the Expression of Uncertainty in Measurement, ISBN 92-67-10188-9, 1st Ed. ISO, Geneva, Switzerland, (1993); see also B. N. Taylor and C. E. Kuyatt, Guidelines for Evaluating and Expressing the Uncertainty of NIST Measurement Results, NIST Technical Note 1297, U. S. Government Printing Office, Washington, DC (1994).

[21] T. H. Wampler, J. Res. Natl. Bur. Stand. (U.S.) 73B, 59-80 (1969) and references therein.

[22] W. R. Miller and G. C. Rhoderick, Fresenius J. Anal. Chem. 351, 221-229 (1995).

About the authors: P. M. Chu, F. R. Guenther, and G. C. Rhoderick are Research Chemists in the Analytical Chemistry Division of the Chemical Sciences and Technology Laboratory. W. J. Lafferty is a Scientist Emeritus in the Optical Technology Division of the Physics Laboratory. The National Institute of Standards and Technology is an agency of the Technology Administration, U. S. Department of Commerce. 